\title{
TOWARD AN UNDERSTANDING OF THE EMOTION-MODULATED STARTLE EYEBLINK REFLEX: THE CASE OF ANGER
}

\author{
A Dissertation \\ by \\ CARLY KATHRYN PETERSON \\ Submitted to the Office of Graduate Studies of \\ Texas A\&M University \\ in partial fulfillment of the requirements for the degree of \\ DOCTOR OF PHILOSOPHY
}

May 2012

Major Subject: Psychology 
Toward an Understanding of the Emotion-modulated Startle Eyeblink Reflex: The Case of Anger

Copyright 2012 Carly Kathryn Peterson 


\title{
TOWARD AN UNDERSTANDING OF THE EMOTION-MODULATED STARTLE EYEBLINK REFLEX: THE CASE OF ANGER
}

\author{
A Dissertation \\ by \\ CARLY KATHRYN PETERSON
}

\begin{abstract}
Submitted to the Office of Graduate Studies of
Texas A\&M University

in partial fulfillment of the requirements for the degree of

DOCTOR OF PHILOSOPHY
\end{abstract}

\begin{abstract}
Approved by:
Chair of Committee, Eddie Harmon-Jones

Committee Members, Gerianne Alexander

Mary Meagher

Brit Grosskopf

Head of Department, Ludy T. Benjamin
\end{abstract}

May 2012

Major Subject: Psychology 


\begin{abstract}
Toward an Understanding of the Emotion-modulated Startle Eyeblink Reflex: The Case of Anger. (May 2012)

Carly Kathryn Peterson, B.S., University of Wisconsin; M.S., College of Liberal Arts Chair of Advisory Committee: Dr. Eddie Harmon-Jones
\end{abstract}

The emotion hypothesis of startle eyeblink modification posits that potentiated eyeblinks are observed in response to fear/disgust (aversive) pictures and eyeblink inhibition occurs in response to pleasant (appetitive) pictures due to the degree to which the stimuli match with the aversive startle probe. Stimuli high in arousal elicit exaggerated responses. Four studies sought to investigate the effect of angering pictures on the startle eyeblink response. Three potential hypotheses were posed: 1) given anger's high levels of arousal and negativity, eyeblinks will be potentiated like those to fear/disgust pictures; 2) given anger's arousing and appetitive qualities, eyeblinks will be inhibited like those to pleasant pictures; 3) anger's arousal, negativity, and approach qualities will balance each other out causing eyeblinks resembling those in response to neutral pictures.

Study 1 supported the third hypothesis in that eyeblinks to angering and neutral pictures did not differ, despite angering pictures being rated higher on arousal and anger 
and lower in valence. These results replicated in Study 2 with a different set of angering pictures. Also, Study 2 demonstrated that dysphoric participants exhibited potentiated eyeblinks during angering pictures much like eyeblinks during fear/disgust stimuli, whereas non-dysphoric participants did not. Ratings of pictures on arousal, valence, and anger did not differ between groups. Constructive patriotism related to inhibited eyeblinks during angering pictures. Study 3 found that dysphoric participants rated angering pictures higher in fear than did non-dysophoric participants, suggesting that the potentiated eyeblinks observed in Study 2 were a result of greater perceived fear. Study 4 again showed that eyeblinks during angering and neutral pictures did not differ, and that constructive patriotism related to inhibited eyeblinks. Taken together, results are consistent with the third hypothesis and suggest that angering stimuli elicit eyeblinks much like those to neutral stimuli due to the competing influences of arousal, valence, and motivation on the startle eyeblink reflex. 


\section{TABLE OF CONTENTS}

Page

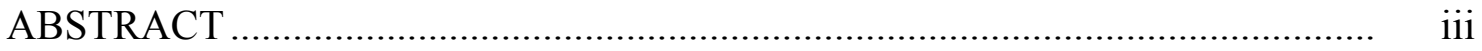

TABLE OF CONTENTS ......................................................................

LIST OF FIGURES .............................................................................. vii

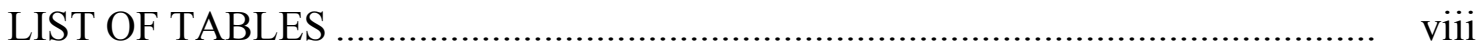

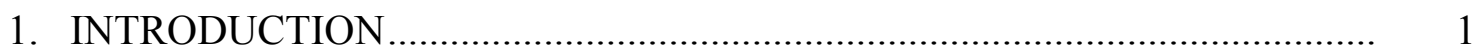

1.1. The Startle Eyeblink as a Defensive Reflex..................................... 1

1.2. Methodology of Examining the Acoustic Startle Eyeblink................ 2

1.3. Anger and Approach Motivation.................................................... 4

1.4. The Anger-modulated Startle Reflex ............................................ 6

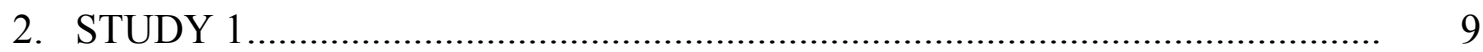

2.1. Method ................................................................................... 9

2.1.1. Participants .............................................................. 9

2.1.2. Materials .................................................................... 9

2.1.3. Procedure .................................................................. 10

2.1.4. Data Collection and Reduction......................................... 10

2.2. Results ................................................................................. 11

2.2.1. Startle Eyeblinks........................................................ 11

2.2.2. Picture Ratings .............................................................. 11

2.3. Discussion ............................................................................... 13

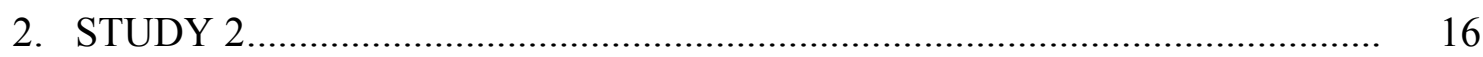

3.1. Method ..................................................................................... 16

3.1.1. Participants .................................................................. 16

3.1.2. Materials ...................................................................... 16

3.1.3. Procedure .................................................................... 17

3.1.4. Data Collection and Reduction...................................... 18

3.2. Results ........................................................................................... 19

3.2.1. Startle Eyeblinks........................................................... 19

3.2.2. Picture Ratings .............................................................. 21

3.2.3. Blind and Constructive Patriotism .................................. 23 


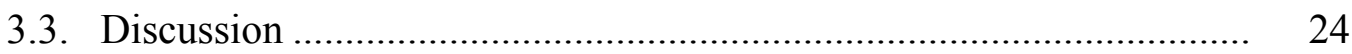

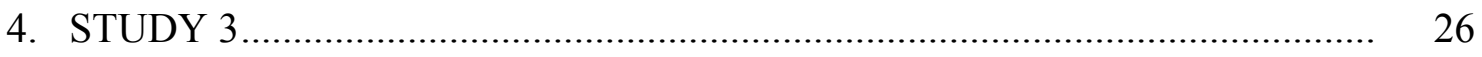

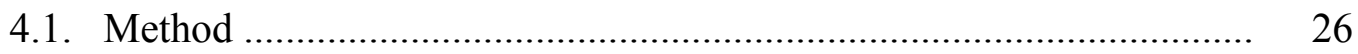

4.1.1. Participants ……………………………………….... 26

4.1.2. Procedure ...................................................................... 26

4.2. Results............................................................................. 27

4.2.1. Picture Ratings .............................................................. 27

4.2.2. Blind and Constructive Patriotism .................................. 33

4.3. Discussion ................................................................................ 34

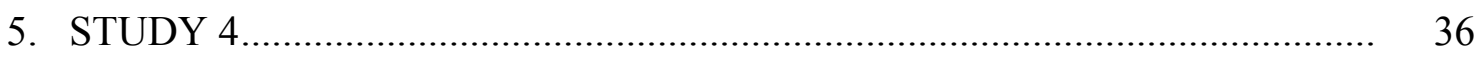

5.1. Method ..................................................................................... 36

5.1.1. Participants and Design .................................................. 36

5.1.2. Materials ……………………………………........... 36

5.1.3. Procedure ................................................................ 39

5.1.4. Data Collection and Reduction......................................... 40

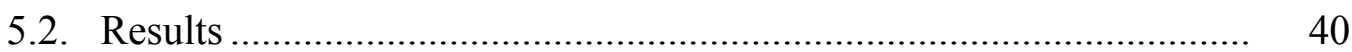

5.2.1. Responses to Pictures as a Function of Essay Expectation................................................................. 40

5.2.2. Relationships between Picture Ratings and Startle Eyeblinks ..................................................................... 45

5.2.3. Relationships between Personality Variables and Responses to Angering Pictures ........................................ 46

5.2.4. Blind and Constructive Patriotism and Picture Ratings .... $\quad 49$ 5.3. Discussion ............................................................................... 51

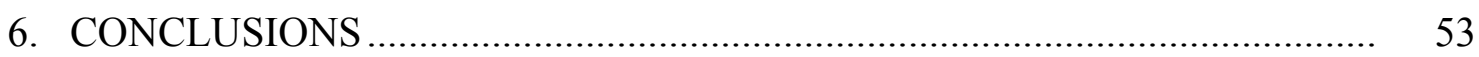

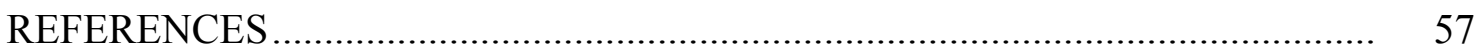

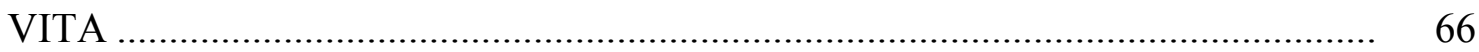




\section{LIST OF FIGURES}

FIGURE Page

$1 \quad$ Startle Eyeblink Magnitudes to all Picture Types in Study 1................... 12

2 Startle Eyeblink Difference Scores to Affective Pictures for Dysphoric and Non-dysphoric Participants in Study 2

3 Startle Eyeblink Magnitudes to all Picture Types as a Function of Essay Expectation in Study 4 


\section{LIST OF TABLES}

TABLE Page

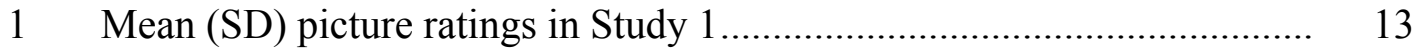

2 Mean (SD) picture ratings for dysphoric and non-dysphoric participants in Study 2 ................................................................... 22

3 Mean (SD) picture ratings for dysphoric and non-dysphoric participants in Study 3

4 Mean (SD) picture ratings as a function of essay expectation in Study 4

$5 \quad$ Mean (SD) personality ratings across all participants and as a function of essay expectation condition in Study 4

6 Zero-order correlations between personality ratings and eyeblink magnitude (affective-neutral) in Study 4 


\section{INTRODUCTION}

\subsection{The startle eyeblink as a defensive reflex}

The startle eyeblink response, a defensive reaction exhibited by animals of various kinds, including humans, traditionally follows a linear pattern during emotional stimuli. Specifically, startle eyeblinks during fear/disgust or aversive stimuli are larger and startle eyeblinks during pleasant or appetitive stimuli are smaller than ones that occur during neutral stimuli (e.g., Vrana et al., 1988). Lang and colleagues (Bradley et al., 1990; Lang et al., 1990) posited that the modulation of such startle responses depended on the match or mismatch of the emotional valence of the foreground with the startle probe. That is, because the startle probe is generally perceived as aversive, stimuli that also prompt an aversive or avoidant reaction elicit a larger response, whereas stimuli that prompt an appetitive reaction inhibit the reflexive aversive response to the startle probe. As such, the startle reflex will either be enhanced or inhibited, depending on whether the emotional valence of the stimuli and the probe match or mismatch. This hypothesis further states that stimuli higher in arousal augment the response (Cuthbert et al., 1996). Arousal is defined as the intensity of the action tendency - in other words, the degree to which the motivation (appetitive or avoidant) will be expressed once activated (Cuthbert et al., 1996). Thus, the stronger the action tendency, the stronger the blink potentiation (negative stimuli) or inhibition (positive stimuli).

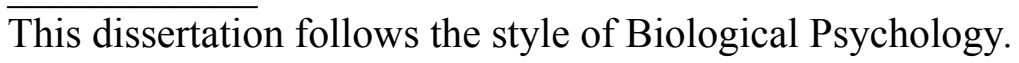


Much of what we know about the neural basis of the startle response in humans comes from animal research. It is known that the primitive neural circuitry involved in the brain's appetitive and avoidant motive systems are subcortical structures such as the sensory thalamus, amygdala, hypothalamus, and the dorsal, ventral, and central gray regions (Lang, 1995). The amygdala is thought to be particularly important in the fear response, having over half a dozen pathways to various targets in the brain that are responsible for hormonal, autonomic, and behavioral reactions (Davis, 1997). Lesion studies have shown that the startle eyeblink response, one of the many fear responses, results from projections from the central nucleus of the amygdala to the nucleus reticularis pontis caudalis in the brainstem (Hitchcock and Davis, 1992). Subsequent activation of spinal and facial motoneurons lead to the physical response in the obicularis oculi muscles in the face, which is how the startle eyeblink response is quantified in humans.

\subsection{Methodology of examining the acoustic startle eyeblink}

Most researchers investigating affective modulation of startle eyeblinks use pictures to elicit emotional states. In this paradigm, participants passively view images depicting blood, gore, and snakes to elicit negative affective states; images such as erotica and skydiving to elicit positive affective states; and neutral images such as wicker baskets and spoons to elicit neutral affective states. Noticeably absent from this literature is research examining anger, a negative affect with uniquely appetitive qualities (for review, see Carver and Harmon-Jones, 2009). Rather, negative affects such as disgust and fear, which are associated with avoidance motivation, are overrepresented 
in these paradigms (Mikels et al., 2005). In fact, to date, anger has been examined in a handful of startle studies, and these studies utilized text-prompted affective imagery rather than affective slides. In these studies, anger-related imagery elicited potentiated startle responses much like those observed during other negative affective imagery such as fear (Cook et al., 1991; Gautier and Cook, 1997; Hawk et al., 1992; Miller et al., 2002) or disgust (Vrana, 1994). It is possible that these potentiated startle responses to angering imagery might be due to a failure to elicit approach-related anger, and that the anger evoked was one mixed with fear or sadness, as has been found in some research (Miller et al., 2002). Only one very recent study on individuals with moderate to severe traumatic brain injury has demonstrated inhibited eyeblinks during angry imagery, and this effect was likely due to impairments in arousal (Neumann et al., 2011).

Another concern with only examining anger in mental imagery paradigms is that the pattern of startle responses has been shown to vary between the standard picture and mental imagery paradigms. Whereas both paradigms result in potentiated blinks in response to fear/disgust stimuli, blink inhibition in response to arousing pleasant imagery has not been observed in paradigms using mental imagery (Cook et al., 1991; Hawk et al., 1992; Miller et al., 2002; Witvliet and Vrana, 1995). Rather, eyeblinks during pleasant mental imagery are larger, similar to those in response to neutral or aversive imagery scripts. This lack of a difference between neutral and pleasant stimuli suggests that mental imagery may not be ideal for understanding the role of emotion and motivation in startle eyeblink responses. 


\subsection{Anger and approach motivation}

Such a discrepancy between paradigms may have implications for more than just responses to pleasant stimuli. Despite anger's negative valence (e.g., Harmon-Jones, 2004), it differs from most negative affects in that it possesses appetitive or approachoriented motivational qualities also shared by some arousing positive affects (HarmonJones, 2003; Harmon-Jones et al., 2009; see Carver and Harmon-Jones, 2009, for a review). That is, rather than causing an avoidant response seen in fear and disgust, anger frequently leads to approach tendencies such as aggression (e.g., Berkowitz, 1993), increased performance on difficult tasks (Mikulincer, 1988), greater visual attention to rewards (Ford et al., 2010), and motor behavior aimed at distance reduction (Wilkowski and Meier, 2010). Anger is also associated with traits such as self-assurance, physical strength, and bravery (Izard, 1991), assertiveness and competitiveness (Buss and Perry, 1992), and behavioral approach sensitivity (Harmon-Jones, 2003).

Anger's identity as an approach-related affect has been further solidified as a result of research on asymmetrical frontal cortical activity and emotion (for a review, see Coan and Allen, 2004). It is thought that emotive processes occur asymmetrically in the prefrontal cortex, so that the left prefrontal cortex is involved in approach motivational processes (Berkman and Lieberman, 2010; Harmon-Jones and Allen, 1997; HarmonJones et al., 2006; Harmon-Jones et al., 2003; Peterson et al., 2008; Sutton and Davidson, 1997) and, conversely, the right prefrontal cortex is involved in withdrawal 
motivational processes (Davidson, 1992; Sutton and Davidson, 1997). Earlier models (and some remaining today) considered "approach" and "withdrawal" to be analogous to "positive" and "negative", suggesting that the differentiation was due to valence rather than motivational direction (e.g., Davidson, 1998; Davidson et al., 1990; Heller, 1990). However, several studies have found that despite anger's negative valence, it is also associated with relative left frontal cortical activation (Harmon-Jones, 2004; HarmonJones, 2007; Harmon-Jones and Allen, 1998; Harmon-Jones and Peterson, 2009; Harmon-Jones et al., 2009; Peterson et al., 2011), providing support for a motivational direction model of frontal asymmetry and emotion.

A recent study examined trait anger in relation to an approach-motivated pattern of startle eyeblink response (Amodio and Harmon-Jones, 2011). In this study, participants viewed positive, negative, and neutral images according to the standard procedure discussed above. In addition, participants' trait emotions were measured by having participants rate to what extent they experienced various emotions and emotionrelated responses. Trait anger, as well as the other approach-oriented emotions such as interest and enjoyment, was associated with startle eyeblink inhibition in response to arousing-positive stimuli. Such novel findings are important as they demonstrate the anger-approach link at the reflex level (Amodio and Harmon-Jones, 2011). 


\subsection{The anger-modulated startle reflex}

Previous research investigating startle eyeblink in response to angering stimuli has been inconclusive because of the concerns related to using imagery described above. Specifically, perhaps anger's approach motivational tendencies are not being evoked by imagery because mixed emotional states are being evoked (e.g., when recalling an angry episode, individuals may also feel guilty over the anger). Also, imagery paradigms have not shown the expected startle eyeblink inhibition during pleasant imagery, suggesting that some other processes may be preventing positive appetitive states from inhibiting the startle response. Because of these concerns with the mental imagery paradigms, it would be important to examine anger using affective slides.

One prediction that could be advanced is that angering stimuli should elicit inhibited eyeblink responses much like pleasant stimuli. Such could be considered the motivation hypothesis. An alternative hypothesis is that anger stimuli may evoke larger blinks because of anger's high levels of arousal and negativity, similar to fear and disgust. If that is the case, then this arousal/valence hypothesis would predict that angering slides will also elicit potentiated eyeblinks (this hypothesis would suggest that affect-modulated startle responses are due to valence/arousal and not motivational direction, as posited by Lang and colleagues). A third hypothesis takes motivation, arousal, and valence into consideration simultaneously. That is, while the motivational properties of anger will inhibit the eyeblink response, its high levels of arousal and negativity will augment the response. But, because these influences will be competing 
against one another, the end result will be somewhere in the middle, much like a response to a neutral picture. In other words, according to this third hypothesis (valence/arousal/motivational direction hypothesis), the affect-modulated startle response is determined by valence, arousal, and motivational direction in combination. Four studies investigate these competing hypotheses. Study 1 used a paradigm much like that used in previous startle studies investigating the effect of emotional pictures on the eyeblink response. However, in addition to displaying pleasant, fear/disgust, and neutral slides, the studies included racist pictures depicting, for example, Klansmen and Nazis, which were designed to make participants low in racial prejudice angry.

The aim of Study 2 was twofold. First, it tested whether the effects of Study 1 would replicate with different angering stimuli. Thus, in this study, angering stimuli consisted of pictures displaying anti-patriotic scenes, such as flag burning and al-Qaeda leader Osama bin Laden. Second, it tested whether eyeblinks in response to angering pictures would differ if the pictures elicited more of a fearful rather than appetitive reaction. Because depression has been characterized by increased sensitivity to avoidant emotional processes and also decreased appetitive emotional processes (e.g., Clark and Watson, 1991; Tomarken and Keener, 1998), it was hypothesized that dysphoric individuals might respond to the angering stimuli with more of a fearful response relative to non-dysphoric participants. Study 3 extended Study 2 by testing if dysphoric 
participants perceive angering pictures as more fear-provoking. Such a response would be consistent with a heightened avoidant reaction evident in the potentiated startle eyeblink response.

The fourth and final study examined the startle reflex in individuals with heightened approach sensitivity, much like Amodio and Harmon-Jones (2011). However, in this case the focus was on how these personality characteristics relate to the anger-modulated startle eyeblink, with predictions that high levels of these traits will predict inhibited eyeblinks. In addition, state approach motivation was manipulated by giving half of the participants the expectation to act against the anti-patriotic imagery (Harmon-Jones et al., 2006). These individuals were predicted to exhibit increased approached motivation as evidenced in inhibited startle eyeblinks during angering pictures, relative to participants who do not have the expectancy to act against antipatriotism. 


\section{STUDY 1}

\subsection{Method}

\subsubsection{Participants}

One-hundred fifty (53 male) Introductory Psychology students participated in exchange for extra credit. For startle eyeblinks, data from eight participants were excluded due to equipment failure, for a total of 142 participants.

\subsubsection{Materials}

Sixty-four pictures were presented in randomized order. Sixteen consisted of racist imagery (e.g., Ku Klux Klan, German Nazis) and were found on the internet; the remaining images were sixteen selected from each of the fear/disgust (e.g., snake, bloody hand), neutral (e.g., spoon, rolling pin), and pleasant (e.g., windsailing, partially nude couple) types of the International Affective Picture System (Lang et al., 2008) ${ }^{1}$. Three neutral picture practice trials preceded the 64 pictures. Each picture trial consisted of a fixation cross which was presented for 1 second, a picture presented for 6 seconds, and an ITI of 14-19 seconds.

The startle probe was a $50 \mathrm{~ms}, 102 \mathrm{~dB}$ burst of white noise presented through stereo headphones. Probes were presented 3.5 or 4.5 seconds after picture onset or 1 second after picture termination. The 3.5 and 4.5 second probes were varied in order to

1. IAPS picture numbers: 1050, 1090, 1200, 1300, 2190, 2200, 2240, 2440, 2480, 2500, 2620, 2850, 2880, 3060, 3150, 3400, 3550, 4672, 4608, 4611, 4641, 4653, 4658, 4659, 4670, 5470, 5500, 5621, 5626, 5731, $6230,7000,7004,7006,7010,7020,7031,7080,7175,7270,7380,8080,8170,8190,8370,9250,9300$, $9405,9500,9620$, and 9630 . 
prevent the individual from learning when the probe would occur and combined for analyses, as is commonly done in startle probe affective picture research (e.g., Patrick et al., 1993). Only startle eyeblinks to probes presented during affective pictures will be discussed in the present research.

\subsubsection{Procedure}

After informed consent was obtained, electrodes were affixed to participants' faces. They then viewed pictures in randomized order while the electromyographic (EMG) signal over the left inferior orbicularis oculi (startle eyeblink) was recorded. Participants were told to ignore the intermittent noises they would hear through the headphones, as was done in most past startle eyeblink research. After the first picture viewing, participants viewed the pictures a second time and rated each on arousal $(1=$ calm, $9=$ excited $)$, valence $(1=$ negative, $9=$ positive $)$, and anger $(1=$ not at all angry, 9 $=$ very angry).

\subsubsection{Data collection and reduction}

To record startle eyeblinks, 4 mm Ag/ $\mathrm{AgCl}$ electrodes (In Vivo Metric, Healdsburg, CA) were placed over the left inferior orbicularis oculi below the inner and outer canthi, as suggested by van Boxtel et al. (1998). Impedance levels were $10 \mathrm{kOhms}$ or below. The electromyographic (EMG) signal was amplified, and frequencies below $30 \mathrm{~Hz}$ and above $500 \mathrm{~Hz}$ were filtered online (Contact Precision Instruments Bio II, Cambridge, MA). Signals were digitally sampled at $1000 \mathrm{~Hz}$. Offline, EMG activity was rectified and then smoothed. The peak magnitude following the onset up to $120 \mathrm{~ms}$ was 
determined. Individual trials were standardized across individuals, then averaged by picture type.

\subsection{Results}

\subsubsection{Startle eyeblinks}

The 4-way (Picture type: angering, pleasant, neutral, fear/disgust) repeatedmeasures analysis of variance (ANOVA) revealed a main effect of Picture Type, $F(3$, $423)=51.35, p<.001$. Startle eyeblinks were greater during fear/disgust pictures $(M=$ $0.22, S D=0.39)$ compared to angering pictures $(M=-0.06, S D=0.28)$, pleasant pictures $(M=-0.23, S D=0.30)$, and neutral pictures $(M=-0.04, S D=0.28), p \mathrm{~s}<.001$. Eyeblinks during pleasant pictures were smaller than eyeblinks during neutral and angering pictures, $p \mathrm{~s}<.001$; angering pictures did not differ from eyeblinks during neutral pictures, $p=.56$. See Figure 1 .

\subsubsection{Picture ratings}

In light of a significant 4 (Picture Type) X 3 (Rating Type: valence, arousal, anger) interaction $[F(6,828)=456.20, p<.001]$, participants' ratings of the pictures were examined using a 4-way (Picture Type) repeated-measures ANOVA for each Rating Type. See Table 1 for means and standard deviations. Data from 3 participants were unusable due to incomplete ratings.

The main effects of Picture Type were significant for ratings of valence, arousal, and anger, $F(3,414) \mathrm{s}=617.87,189.34$, and $375.71, p \mathrm{~s}<.001$, respectively. Pleasant pictures were perceived as more positive and more arousing than the other picture types, $p$ s $<.001$. Neutral pictures were more positive than the angering and fear/disgust 


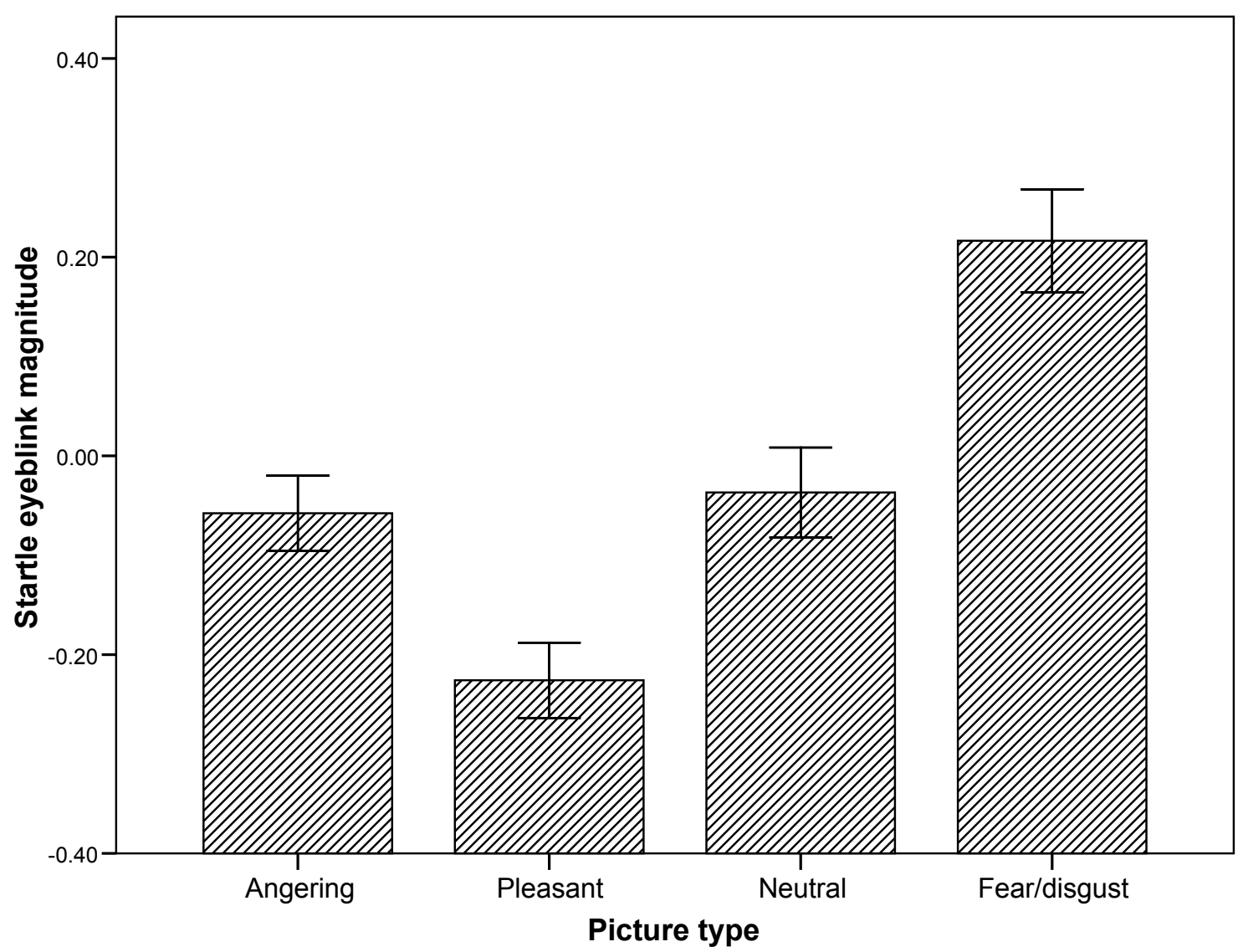

Figure 1. Startle eyeblink magnitudes to all picture types in Study 1 (error bars indicate $95 \%$ confidence intervals).

pictures $(p \mathrm{~s}<.001)$, which were equally negative $(p=.51)$ and more arousing than neutral pictures $(p \mathrm{~s}<.001)$. Fear/disgust pictures were more arousing than angering pictures $(p<.001)$ and more angering than pleasant and neutral pictures, $p$ s $<.001$. As expected, the angering pictures were significantly more angering than all other picture types, $p$ s $<.001$. Ratings of anger for pleasant and neutral pictures did not differ, $p=.87$. 
Table 1

Mean (SD) picture ratings in Study 1

\begin{tabular}{lccrr}
\hline & \multicolumn{4}{c}{ Picture Type } \\
\cline { 2 - 5 } & Angering & Pleasant & Neutral & Fear/disgust \\
\hline Valence & $1.86(1.04)^{\mathrm{a}}$ & $5.94(1.37)^{\mathrm{b}}$ & $4.00(1.54)^{\mathrm{c}}$ & $1.78(0.80)^{\mathrm{a}}$ \\
Arousal & $3.35(2.16)^{\mathrm{a}}$ & $4.78(1.57)^{\mathrm{b}}$ & $1.85(1.01)^{\mathrm{c}}$ & $3.79(2.27)^{\mathrm{d}}$ \\
Anger & $5.44(2.02)^{\mathrm{a}}$ & $1.25(0.50)^{\mathrm{b}}$ & $1.23(0.38)^{\mathrm{b}}$ & $3.56(1.76)^{\mathrm{c}}$ \\
\hline
\end{tabular}

Note. Within each rating type, means with significant differences $(p<.05)$ are denoted by different superscripts.

Correlations between picture ratings and eyeblinks within each picture type revealed a significant inverse relationship between eyeblink magnitude and ratings of valence for fear/disgust stimuli. Potentiated eyeblinks were associated with lower (i.e. more negative) ratings, $r(138)=-.20, p<.05$. There was a trend for eyeblinks during fear/disgust pictures to be associated with higher ratings of anger, $r(138)=.15, p=.08$. No other significant relationships were found, $r \mathrm{~s}<.15, p \mathrm{~s}>.10$.

\subsection{Discussion}

Study 1 replicated much previous work in line with the emotional valence/arousal hypothesis (Lang et al., 1990) showing that startle probes presented during fear/disgust stimuli elicited much larger eyeblink responses than probes presented during pleasant and neutral stimuli. Ratings of valence and arousal indicated that pleasant pictures were perceived as more positive and more arousing than neutral and fear/disgust pictures, whereas fear/disgust pictures were more arousing and more negative than neutral pictures. 
New to the present research is that no discernable differences were found between startle eyeblinks during angering and neutral pictures, despite the angering pictures being rated higher on anger and arousal and more negative in valence. In fact, the angering and fear/disgust pictures were rated equally negative, yet fear/disgust pictures elicited larger blinks. The emotion hypothesis predicted that such a negative emotional response to the angering pictures should cause potentiated eyeblinks much like those to fear/disgust pictures, which was clearly not the case. It is possible that the greater arousal of the fear/disgust stimuli compared to the anger stimuli contributed to the potentiated eyeblinks. However, if that were the case, the more arousing angering pictures should have elicited larger eyeblinks than the less arousing neutral pictures, and this was not the case.

Another hypothesis predicted that, given its approach motivational quality, angering pictures should cause inhibited eyeblinks like those in response to pleasant pictures. This was also not supported as angering pictures elicited larger eyeblinks than did pleasant pictures. Again, the arousal of the pleasant stimuli might have caused relatively greater eyeblink inhibition, but that does not explain why neutral and angering pictures did not differ.

The most likely and most supported hypothesis is the third, which predicted that the competing influences of arousal, valence, and motivational direction would cause eyeblinks during angering pictures to resemble those during neutral pictures. That is, even though angering pictures are more negative in valence and higher in arousal than neutral pictures, which would predict potentiated eyeblinks, the influence of anger's 
approach motivational qualities that tend to inhibit eyeblinks cancels out the former. As such, the resulting response resembles that to neutral pictures.

Although this pattern of responses is in line with predictions and is based on theory, we wanted to see if it would replicate using a different set of angering pictures.

To test this we ran an additional experiment using angering stimuli portraying anti-U.S. imagery such as flag burning and the attack on the World Trade Center. Aside from changes in these angering stimuli, the paradigm remained virtually the same. A second aim to the experiment was to see if angering pictures would produce larger eyeblink responses under more aversive circumstances, such as depression. Research has shown that depressed individuals lack sensitivity to appetitive emotional processes while showing heightened sensitivity to aversive emotional processes. As such, in Study 2, angering, pleasant, neutral, and fear/disgust stimuli were also viewed by individuals with dysphoria $^{2}$ as well as individuals from the general population. It was hypothesized that angering images would evoke larger eyeblink responses in dysphoric participants but not controls. No other differences are expected.

2. The terms "dysphoria" and "dysphoric" are used in this research in light of the fact that this is not a true clinical sample. No clinical interviews were conducted to make a diagnosis of depression, although scores on the BDI-II are indicative of depressive tendencies. 


\section{STUDY 2}

\subsection{Method}

\subsubsection{Participants}

Participants were part of a larger group of Introductory Psychology students who completed the Beck Depression Inventory - II (BDI-II; Beck et al., 1996) prior to the experiment and were eligible to participate in the study if their scores were in the bottom and top quartiles. A total of 38 (12 male) students participated in the experiment; three participants did not fully complete the study and data from six participants were excluded due to equipment failure, leaving 29 participants (dysphoric: $n=14$; nondysphoric: $n=15)$.

\subsubsection{Materials}

Sixty-four pictures were presented in randomized order. Sixteen consisted of anti-patriotic/anti-U.S. imagery (e.g. flag burning, Osama Bin Laden) and were found on the internet; the remaining images were those used in Study 1. As in Study 1, the startle probe was a $50 \mathrm{~ms}, 102 \mathrm{~dB}$ burst of white noise presented either 3.5 or 4.5 seconds during picture presentation or 1 second after picture termination. Only startle eyeblinks to probes presented during affective pictures will be discussed in the present research.

The BDI-II (Beck et al., 1996) was administered to assess symptoms of depression. The 21-item instrument is used widely in clinical and laboratory settings to measure physiological (e.g., changes in sleep and appetite), affective (e.g., sadness), and cognitive (e.g., guilt, hopelessness) components of depression. Responses were given 
using a scale of 0 to 3 with 3 being the most severe. Although all participants completed the BDI-II as a prerequisite for the study, it was re-administered during the experiment to assess current symptomatology. The current scores were then averaged with their previous scores and a median split determined condition (dysphoric: $M=12.39, S D=$ 2.76; non-dysphoric: $M=1.85, S D=2.02 ; t(24)=10.76, p<.001)$.

Schatz et al.’s (1999) 19-item Patriotism questionnaire was administered to assess individual differences in blind and constructive patriotism. Blind patriotism, measured with 12 items (e.g., "People who do not wholeheartedly support America should live somewhere else" and "The United States is virtually always right") has been shown to relate to such things as political disengagement and perceptions of foreign threat. In contrast, 7 items assessing constructive patriotism (e.g., "If I criticize the United States, I do so out of love for my country" and "I express my love for America by supporting efforts at positive change") have been associated with indicators of political involvement such as interest and knowledge. Participants indicated their attitudes on a 5point scale from 1 (strongly disagree) to 5 (strongly agree).

\subsubsection{Procedure}

After informed consent was obtained, participants completed the BDI-II and Patriotism questionnaires. Electrodes were affixed to their face. Participants then viewed pictures in randomized order while startle eyeblink was recorded. As in Study 1, participants were told to ignore the intermittent noises they would hear through the headphones. After the first picture viewing, participants viewed the pictures a second 
time and rated each on arousal $(1=$ calm, $9=$ excited $)$, valence $(1=$ negative, $9=$ positive $)$, and anger $(1=$ not at all angry, $9=$ very angry $)$.

\subsubsection{Data collection and reduction}

To record startle eyeblinks, two 9-mm tin electrodes (Electro-Cap International, Eaton, $\mathrm{OH}$ ) were placed over the left inferior orbicularis oculi below the inner and outer canthi. Impedance levels were 10 kilo-ohms or below. The EMG signal was amplified online with Neuroscan Synamps (El Paso, TX), bandpass filtered (0.1 to $500 \mathrm{~Hz} ; 60 \mathrm{~Hz}$ notch filter enabled) and digitized at $2000 \mathrm{~Hz}$. Offline, frequencies below $30 \mathrm{~Hz}$ and above $500 \mathrm{~Hz}$ were filtered ( $24 \mathrm{~dB}$ rolloff). EMG activity then was rectified and smoothed prior to baseline correction. The peak magnitude 20-120 ms following onset was determined.

Eyeblinks were visually inspected and trials in which there was excessive noise in the signal, or in which a spontaneous blink occurred either immediately preceding stimulus onset or in the interval between stimulus onset and the minimal blink onset latency were rejected (cf. Blumenthal et al., 2005). Double blinks were also cause for rejection. Trials in which there were no response were not rejected although two individuals who did not show any responses were classified as nonresponders (Blumenthal et al., 2005) and were not included in analyses. Data from one additional participant were not used due to more than half of trials in a given picture type being rejected, leaving a final sample of 26 participants for data analyses (dysphoric: $n=13$; non-dysphoric: $n=13$ ). Individual trials were standardized within individuals, then averaged by picture type. 


\subsection{Results}

\subsubsection{Startle eyeblinks}

A 2 (Group: non-dysphoric, dysphoric) X 4 (Picture Type: angering, pleasant, neutral, fear/disgust) ANOVA revealed a main effect of Picture Type replicating Study $1, F(3,72)=12.32, p<.001$. Across all participants, startle eyeblinks during fear/disgust pictures $(M=0.32, S D=0.29)$ were larger than eyeblinks during all other picture types $(p \mathrm{~s}<.02)$. Eyeblinks during pleasant pictures $(M=-0.21, S D=0.31)$ were smaller than eyeblinks during neutral $(M=0.06, S D=0.39)$ and angering $(M=0.11, S D=0.36)$ pictures, $p \mathrm{~s}<.01$; angering pictures did not differ from eyeblinks during neutral pictures, $p=.63$. The main effect of Group was $n s$.

There was a marginal interaction of Group X Picture Type, $F(3,73)=2.51, p=$ .07 . For non-dysphoric participants, fear/disgust pictures $(M=0.30, S D=.32)$ elicited larger eyeblinks than did angering $(M=-0.07, S D=0.24)$ and pleasant $(M=-0.18, S D=$ $0.25)$ pictures $(p s<.01)$. Fear/disgust pictures elicited marginally greater eyeblinks compared to neutral pictures $(M=0.09, S D=0.49), p=.09$. Eyeblinks during pleasant pictures were smaller than eyeblinks during neutral pictures $(p<.05)$ and eyeblinks during angering pictures did not differ from those during pleasant and neutral pictures, $p \mathrm{~s}>$.19. A different pattern emerged for dysphoric participants. Fear/disgust pictures $(M=0.33, S D=0.27)$ elicited larger eyeblinks than did pleasant $(M=-0.24, S D=0.37)$ and neutral $(M=0.03, S D=0.27)$ pictures $(p s<.02)$, but did not differ from eyeblinks during angering pictures $(M=0.28, S D=0.39), p=.66$. Eyeblinks during angering pictures were larger than those during neutral pictures, $p<.05$. Eyeblinks during 
pleasant pictures were smaller than eyeblinks during neutral and fear/disgust pictures, $p \mathrm{~s}$ $<.03$. Only eyeblinks during angering pictures differed between groups, so that dysphoric participants showed larger eyeblinks than non-dysphoric participants, $p<.01$ (all other $p \mathrm{~s}>.61$ ).

Because of our interest in assessing the effects of dysphoria on anger in particular, we created affective picture type minus neutral pictures scores and subjected these difference scores to an ANOVA. The main effect of Picture Type was significant, $F(2,48)=25.09, p<.001$, revealing a linear pattern of eyeblinks, with the largest eyeblinks during fear/disgust pictures $(M=0.25, S D=0.50)$, followed by angering pictures $(M=0.04, S D=0.53)$ and then pleasant pictures $(M=-0.27, S D=0.48), p \mathrm{~s}<$ .01 . The main effect of group was $n s$.

As seen in Figure 2, the Group X Picture Type interaction was significant, $F(2$, $48)=4.20, p<.05$. For non-dysphoric participants, eyeblinks during fear/disgust pictures $(M=0.21, S D=0.67)$ were larger than those during angering $(M=-0.16, S D=$ $0.44)$ and pleasant $(M=-0.27, S D=0.53)$ pictures, $p \mathrm{~s}<.001$. Eyeblinks during angering and pleasant pictures did not differ, $p=.32$. For dysphoric participants, eyeblinks were smallest during pleasant pictures $(M=-0.28, S D=0.45), p \mathrm{~s}<.001$. Eyeblinks during angering $(M=0.25, S D=0.55)$ and fear/disgust $(M=0.30, S D=0.25)$ pictures did not differ, $p=.61$. Again, only eyeblinks during angering pictures differed between groups, so that dysphoric participants exhibited larger eyeblinks than non-dysphoric participants, $p<.05$ (all other $p$ s $>.64$ ). 


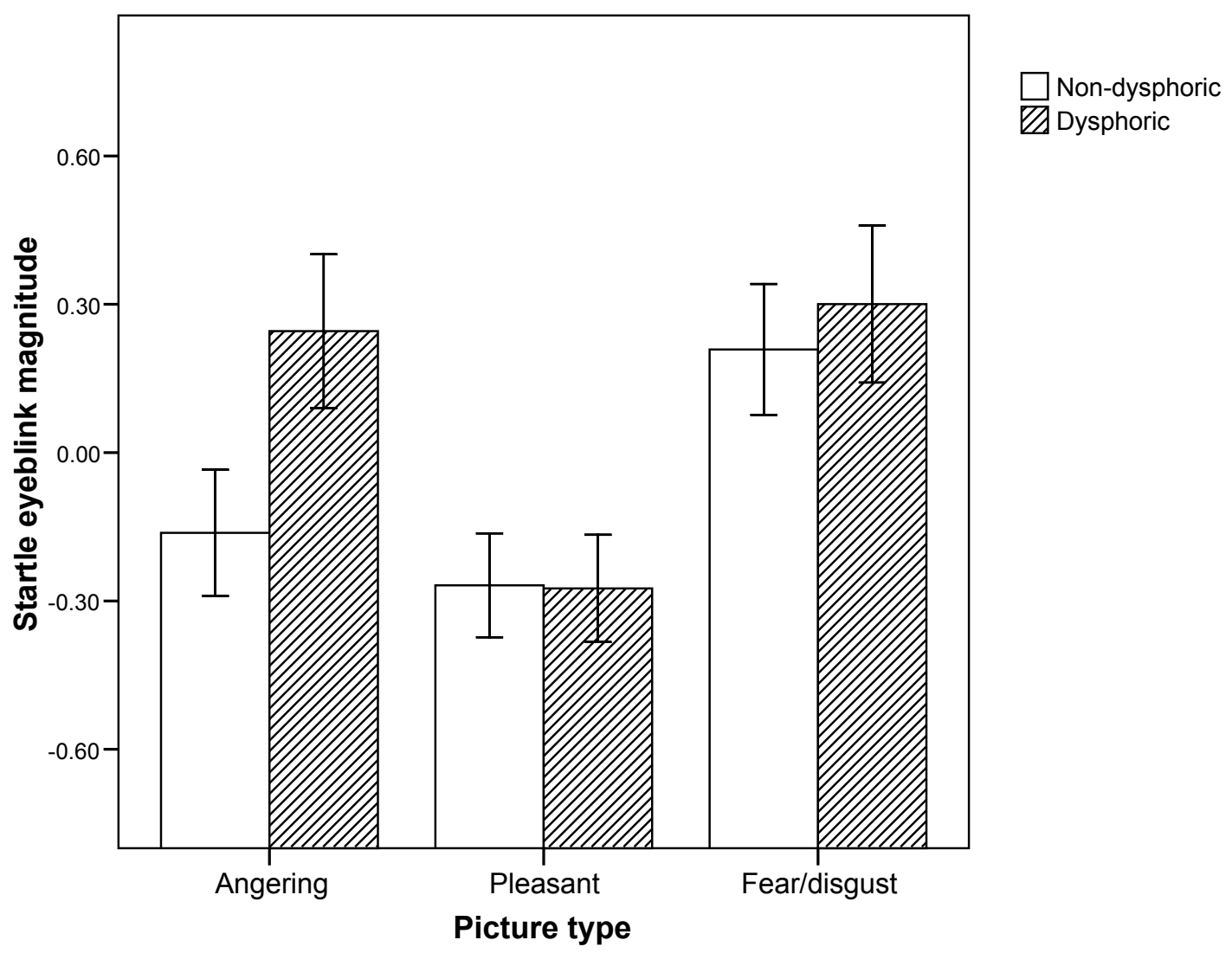

Figure 2. Startle eyeblink difference scores (affective - neutral) to affective pictures for dysphoric and non-dysphoric participants in Study 2 (error bars indicate 95\% confidence intervals).

\subsubsection{Picture ratings}

Between-group means and standard deviations for picture ratings are presented in Table 2. Participants' ratings of the pictures were examined using a Group X Picture Type repeated-measures ANOVA for each Rating Type (valence, arousal, anger), as done in Study 1. 
Table 2

Mean (SD) picture ratings for dysphoric and non-dysphoric participants in Study 2

\begin{tabular}{|c|c|c|}
\hline \multirow[t]{2}{*}{ Rating/picture type } & \multicolumn{2}{|c|}{ Condition } \\
\hline & Non-dysphoric & Dysphoric \\
\hline \multicolumn{3}{|l|}{ Valence } \\
\hline Angering & $4.04(1.79)$ & $3.24(1.69)$ \\
\hline Pleasant & $7.64(1.61)$ & $6.28(1.38)$ \\
\hline Neutral & $7.85(1.71)$ & $5.67(1.30)$ \\
\hline Fear/disgust & $3.94(1.70)$ & $3.40(0.93)$ \\
\hline \multicolumn{3}{|l|}{ Arousal } \\
\hline Angering & $3.94(2.36)$ & $2.46(1.80)$ \\
\hline Pleasant & $3.86(1.82)$ & $3.49(1.73)$ \\
\hline Neutral & $1.68(1.31)$ & $1.40(0.71)$ \\
\hline Fear/disgust & $3.94(1.86)$ & $2.51(1.47)$ \\
\hline \multicolumn{3}{|l|}{ Anger } \\
\hline Angering & $4.51(2.37)$ & $4.71(1.88)$ \\
\hline Pleasant & $1.38(0.86)$ & $1.67(1.15)$ \\
\hline Neutral & $1.18(0.45)$ & $1.39(0.67)$ \\
\hline Fear/disgust & $2.78(1.85)$ & $3.43(1.80)$ \\
\hline
\end{tabular}

For valence, the main effects of Group and Picture Type were significant, $F(1$, $24)=14.21$ and $F(3,72)=39.65, p s<.001$. Across all participants, neutral $(M=6.76$, $S D=1.86)$ and pleasant $(M=6.96, S D=1.63)$ pictures were rated more positively than fear/disgust $(M=3.67, S D=1.37)$ and angering $(M=3.64, S D=1.76)$ pictures $(p s<$ $.001)$. Ratings of valence did not differ between neutral and pleasant pictures, $p=.63$, or between angering and fear/disgust pictures, $p=.94$. Dysphoric participants perceived the 
pictures in general as more negative, $p<.001$. The Group $\mathrm{x}$ Picture Type interaction was not significant, $F=1.52, p=.21$.

For arousal, only the main effect of Picture Type was significant $[F(3,72)=$ $19.97, p<.001]$, which indicated that, across all participants, angering $(M=3.20, S D=$ 2.19), fear/disgust $(M=3.23, S D=1.80)$, and pleasant $(M=3.67, S D=1.75)$ pictures did not differ from each other $(p s>.19)$, but were all more arousing than neutral pictures $(M=1.54, S D=1.04), p \mathrm{~s}<.001$. The main effect of Group and Group X Picture Type interaction were not significant, $F_{\mathrm{s}}<2.00, p \mathrm{~s}>.17$.

For anger, only the main effect of Picture Type was significant, $F(3,72)=33.93$, $p<.001$. Angering pictures $(M=4.61, S D=2.10)$ were perceived as being more angering than fear/disgust $(M=3.11, S D=1.82)$, pleasant $(M=1.52, S D=1.01)$, and neutral $(M=1.29, S D=0.57)$ pictures, $p \mathrm{~s}<.001$. Fear/disgust pictures were more angering than pleasant and neutral pictures, $p \mathrm{~s}<001$; the latter did not differ, $p=.53$. The main effect of Group and Group X Picture Type interaction were not significant, Fs $<0.80, p s>.37$.

Correlations between picture ratings and startle eyeblinks within each picture type did not reveal any significant relationships, $r \mathrm{~s}<.33, p \mathrm{~s}>.10$.

\subsubsection{Blind and constructive patriotism}

Independent t-tests were used to assess group differences on the Patriotism questionnaire. Neither blind nor constructive patriotism differed between dysphoric (blind: $M=31.18, S D=6.73$; constructive: $M=23.62, S D=2.18$ ) and non-dysphoric participants (blind: $M=32.69, S D=6.76$; constructive: $M=22.90, S D=3.08$ ), $t \mathrm{~s}<0.66$, 
$p \mathrm{~s}>.51$. As such, it is unlikely that any group differences in patriotism contributed to differences in dysphoric reactions to the (anti-patriotic) angering pictures.

Zero-order correlations revealed that constructive patriotism was associated with inhibited eyeblinks during angering pictures, $r=-.42, p<.05$. Patriotism did not relate to other eyeblink responses, $r \mathrm{~s}<.33, p \mathrm{~s}>.11$.

\subsection{Discussion}

Replicating Study 1, Study 2 showed a linear pattern of eyeblinks to affective pictures across all participants, with eyeblinks being greatest during fear/disgust pictures, followed by neutral and pleasant pictures. Also like Study 1, startle eyeblinks during angering pictures did not differ from eyeblinks during neutral pictures, despite being rated higher in arousal and anger and lower in valence. In Study 2, angering pictures were rated as arousing as fear/disgust pictures. Additionally, anger-related eyeblink inhibition was associated with constructive patriotism, suggesting that these participants were particularly sensitive to appetitive motivational processes.

When participants were separated into two groups, however, a different pattern emerged. For non-dysphoric participants, eyeblinks during angering pictures did not differ from those during pleasant and neutral pictures but were smaller than eyeblinks during fear/disgust pictures. On the other hand, dysphoric participants evidenced eyeblinks during angering pictures much like eyeblinks during fear/disgust pictures. While this equality is consistent with the emotion hypothesis proposed by Lang et al., (1990), given that both the angering and fear/disgust stimuli were arousing and negative in valence, it is also consistent with the motivation hypothesis assuming that the 
angering pictures did not elicit approach-related anger as expected. However, there was no evidence that dysphoric participants rated the angering pictures any differently on valence, arousal, or anger relative to non-dysphoric participants. If dysphoric participants didn't perceive the angering pictures any differently on those dimensions, why did they show potentiated eyeblinks suggestive of a more avoidant reaction to them?

To further clarify why dysphoric participants showed startle eyeblinks during angering pictures similar to those during fear/disgust pictures, we conducted a third study in which participants rated each of the 64 pictures on additional variables. That is, in addition to valence, arousal, and anger, which were included in the previous two studies, in Study 3 all images were also rated on fear, disgust, joy, sadness, and anxiety. We were particularly interested in ratings of fear given our hypothesis in Study 2 that dysphoric individuals would exhibit larger eyeblinks to angering pictures due to a more aversive or defensive reaction to them as opposed to approach-related anger. As such, we hypothesized that dysphoric participants, compared to non-dysphoric participants, would rate the angering stimuli higher on fear and perhaps anxiety due to their avoidance qualities. We did not have any a priori predictions for the remaining ratings. 


\section{STUDY 3}

\subsection{Method}

\subsubsection{Participants}

One hundred ninety-six (52 male) Introductory Psychology students participated in exchange for partial course credit. Data from nine participants were excluded due to failure to complete the BDI-II. Because this was an online study more susceptible to noise, we also excluded participants $(n=3)$ if more than $95 \%$ of fear/disgust and pleasant photos were rated more than 2.5 standard deviations from the picture valence mean. Thus, there were 184 participants for data analysis (using the same BDI-II cutoff as in Study 2, non-dysphorics: $n=114$, dysphorics: $n=70$ ).

\subsubsection{Procedure}

Participants completed the survey online. They were instructed to view each image and then rate it on how it made them feel on the following constructs: valence (1 $=$ negative, $9=$ positive $)$, arousal $(1=$ calm, $9=$ excited $)$, anger, fear, disgust, joy, sadness, and anxiety (for each emotion: $1=$ not at all, $9=$ very much so). Each picture was presented individually. After viewing all images, participants completed the Patriotism questionnaire and BDI-II (non-dysphoric: $M=2.42, S D=2.37$; dysphoric: $M$ $=15.44, S D=7.96 ; t(182)=16.34, p<.001)$. 


\subsection{Results}

\subsubsection{Picture ratings}

Between-group means and standard deviations for picture ratings are presented in

Table 3. As done in the previous studies, participants' ratings of the pictures were examined using a Group X Picture Type repeated-measures ANOVA for each Rating Type (valence, arousal, anger, fear, disgust, joy, sadness, anxiety).

Table 3

Mean (SD) of picture ratings for dysphoric and non-dysphoric participants in Study 3

\begin{tabular}{|c|c|c|}
\hline \multirow[t]{2}{*}{ Rating/Picture Type } & \multicolumn{2}{|c|}{ Mean (SD) } \\
\hline & Non-dysphoric & Dysphoric \\
\hline \multicolumn{3}{|l|}{ Valence } \\
\hline Anger & $2.68(1.40)$ & $2.44(1.26)$ \\
\hline Pleasant & $7.47(1.05)$ & $7.11(1.10)$ \\
\hline Neutral & $6.37(1.31)$ & $6.05(1.27)$ \\
\hline Fear/disgust & $2.96(1.37)$ & $2.50(1.16)$ \\
\hline \multicolumn{3}{|l|}{ Arousal } \\
\hline Anger & $4.31(2.21)$ & $5.18(2.10)$ \\
\hline Pleasant & $4.30(1.57)$ & $5.11(1.76)$ \\
\hline Neutral & $1.68(0.85)$ & $2.12(0.99)$ \\
\hline Fear/disgust & $4.47(2.06)$ & $5.32(1.98)$ \\
\hline \multicolumn{3}{|l|}{ Anger } \\
\hline Anger & $6.09(2.08)$ & $6.45(2.06)$ \\
\hline Pleasant & $1.17(0.51)$ & $1.36(0.61)$ \\
\hline Neutral & $1.15(0.41)$ & $1.37(0.69)$ \\
\hline Fear/disgust & $2.80(1.66)$ & $3.55(1.84)$ \\
\hline
\end{tabular}


Table 3 Continued

\begin{tabular}{|c|c|c|}
\hline \multirow[t]{2}{*}{ Rating/Picture Type } & \multicolumn{2}{|c|}{ Mean (SD) } \\
\hline & Non-dysphoric & Dysphoric \\
\hline \multicolumn{3}{|l|}{ Fear } \\
\hline *Anger & $4.29(2.29)$ & $5.41(2.15)$ \\
\hline *Pleasant & $1.65(0.62)$ & $2.17(0.97)$ \\
\hline Neutral & $1.28(0.52)$ & $1.55(0.64)$ \\
\hline *Fear/disgust & $4.70(1.96)$ & $5.47(1.87)$ \\
\hline \multicolumn{3}{|l|}{ Disgust } \\
\hline Anger & $5.92(2.10)$ & $6.29(2.11)$ \\
\hline Pleasant & $1.46(0.77)$ & $1.78(0.91)$ \\
\hline Neutral & $1.22(0.44)$ & $1.41(0.71)$ \\
\hline Fear/disgust & $5.42(1.63)$ & $6.11(1.48)$ \\
\hline \multicolumn{3}{|l|}{ Joy } \\
\hline Anger & $1.16(0.26)$ & $1.27(0.45)$ \\
\hline Pleasant & $4.31(1.65)$ & $4.47(1.86)$ \\
\hline Neutral & $1.76(0.88)$ & $2.00(0.97)$ \\
\hline Fear/disgust & $1.13(0.28)$ & $1.19(0.38)$ \\
\hline \multicolumn{3}{|l|}{ Sadness } \\
\hline Anger & $4.75(1.97)$ & $5.28(2.10)$ \\
\hline Pleasant & $1.21(0.47)$ & $1.47(0.65)$ \\
\hline Neutral & $1.59(0.72)$ & $1.92(0.86)$ \\
\hline Fear/disgust & $3.46(1.48)$ & $3.92(1.52)$ \\
\hline \multicolumn{3}{|l|}{ Anxiety } \\
\hline Anger & $4.03(2.18)$ & $4.92(2.10)$ \\
\hline Pleasant & $2.19(1.17)$ & $2.88(1.47)$ \\
\hline Neutral & $1.38(0.69)$ & $1.68(0.81)$ \\
\hline Fear/disgust & $4.25(1.88)$ & $5.05(1.87)$ \\
\hline
\end{tabular}

Note. * denotes means which differ significantly $(p<.05)$ between groups. 


\subsubsection{Valence}

As in Study 2, only main effects of Group and Picture Type were significant, $F(1,182)=7.28, p<.01$ and $F(3,546)=880.90, p<.001$, respectively. Across all participants, pleasant pictures $(M=7.33, S D=1.08)$ were rated more positively than all other picture types, $p \mathrm{~s}<.001$. Neutral pictures $(M=6.25, S D=1.30)$ were rated more positively than angering $(M=2.59, S D=1.35)$ and fear/disgust $(M=2.79, S D=1.31)$ pictures $(p \mathrm{~s}<.001)$; the latter differed marginally, $p=.08$. Dysphoric participants rated all pictures more negatively than non-dysphoric participants, $p<.01$. The Group $\mathrm{X}$ Picture Type interaction was not significant, $F=0.34, p=.79$.

\subsubsection{Arousal}

Similarly, for arousal, the main effects of Group and Picture Type were also significant, $F(1,182)=12.04$ and $F(3,546)=253.29, p \mathrm{~s}<.001$, respectively. Across all participants, neutral pictures $(M=1.85, S D=0.93)$ were significantly less arousing than angering $(M=4.64, S D=2.21)$, pleasant $(M=4.61, S D=1.69)$, and fear/disgust $(M=$ $4.79, S D=2.06)$ pictures $(p \mathrm{~s}<.001)$, which did not differ, $p \mathrm{~s}>.13$. Dysphoric participants rated all pictures as more arousing than non-dysphoric participants, $p<.001$. The Group X Picture Type interaction was not significant, $F=1.28, p=.28$.

\subsubsection{Anger}

For anger ratings, the main effects of Group and Picture Type were significant, $F(1,182)=7.12, p<.01$, and $F(3,546)=668.33, p<.001$, respectively. Across all participants, angering pictures $(M=6.23, S D=2.07)$ were rated as more angering than all other picture types, $p \mathrm{~s}<.001$. Fear/disgust pictures $(M=3.09, S D=1.76)$ were more 
angering than neutral $(M=1.24, S D=0.54)$ and pleasant $(M=1.24, S D=0.56)$ pictures $(p \mathrm{~s}<.001)$, although the latter did not differ, $p=.94$. Dysphoric participants rated the pictures as more angering than non-dysphoric participants, $p<.01$. The Group X Picture Type interaction was not significant, $F=1.97, p=.12$.

\subsubsection{Fear}

For fear ratings, the main effects of Group $[F(1,182)=14.96, p<.001]$ and Picture Type $[F(3,546)=426.70, p<.001]$ were significant. Across all participants, fear/disgust pictures $(M=4.99, S D=1.96)$ elicited more fear than all other picture types, $p \mathrm{~s}<.05$. Angering pictures $(M=4.71, S D=2.30)$ caused more fear than neutral $(M=$ $1.39, S D=0.58)$ and pleasant $(M=1.85, S D=0.81)$ pictures $(p s<.001)$, whereas neutral pictures caused less fear than pleasant pictures, $p<.001$. Dysphoric participants rated all pictures higher on fear than non-dysphoric participants, $p<.001$.

The Group X Picture Type interaction was also significant, $F(3,546)=3.83, p<$ .01 . For non-dysphoric participants, the pattern of ratings was analogous to the main effect of Picture Type described above, $p \mathrm{~s}<.03$. However, for dysphoric participants, ratings of fear for angering pictures did not differ from ratings for fear/disgust pictures, $p$ $=.78$, suggesting that they perceived the angering pictures to be as fear-provoking as the fear/disgust pictures. Dysphoric participants rated the angering, pleasant, and fear/disgust pictures as more fearful than non-dysphoric participants, $p \mathrm{~s}<.05$. Ratings did not differ for neutral pictures, $p=.25$.

Because of our interest in assessing the effects of dysphoria on anger in particular, we created affective picture type minus neutral pictures ratings scores for fear 
and subjected these difference score to an ANOVA. The main effects of Group $[F(1$, $182)=7.03, p<.01]$ and Picture Type $[F(2,364)=339.40, p<.001]$ were significant. Across all participants, fear/disgust pictures $(M=3.60, S D=1.77)$ were the most fearprovoking, followed by angering pictures $(M=3.33, S D=2.22)$ and then pleasant pictures $(M=0.46, S D=0.72), p s<.05$. In general, dysphoric participants rated all pictures as more fear-provoking compared to non-dysphoric participants, $p<.01$. The Group X Picture Type interaction was marginally significant, $F(2,364)=2.53, p=.08$. For non-dysphoric participants, the pattern of ratings was analogous to the main effect of picture type described above, $p \mathrm{~s}<.02$. However, for dysphoric participants, ratings of fear for angering pictures again did not differ from ratings for fear/disgust pictures, $p=$

.79. Dysphoric participants rated the angering and fear/disgust pictures as more fearful than non-dysphoric participants, $p<.001$ and $p=.05$, respectively. Ratings did not differ for pleasant pictures, $p=.34$.

\subsubsection{Disgust}

For disgust ratings, the main effects of Group and Picture Type were significant, $F(1,182)=7.56, p<.01$ and $F(3,546)=797.48, p<.001$, respectively. Across all participants, angering pictures $(M=6.06, S D=2.11)$ were rated as more disgusting than all other pictures $(p \mathrm{~s}<.01)$, followed by fear/disgust pictures $(M=5.68, S D=1.61), p \mathrm{~s}$ $<.001$. Neutral pictures $(M=1.29, S D=0.57)$ were less disgusting than pleasant pictures $(M=1.58, S D=0.84), p<.05$. Dysphoric participants perceived the pictures as more disgusting than non-dysphoric participants, $p<.01$. The Group X Picture Type interaction was not significant, $F=1.32, p=.27$. 


\subsubsection{Joy}

For joy ratings, only the main effect of Picture Type was significant, $F(3,546)=$ 482.73, $p<.001$. Pleasant pictures $(M=4.37, S D=1.73)$ were more joyful than all other picture types, $p \mathrm{~s}<.001$. Neutral pictures $(M=1.85, S D=0.92)$ were more joyful than both angering $(M=1.20, S D=0.35)$ and fear/disgust $(M=1.16, S D=0.32)$ pictures $(p \mathrm{~s}$ $<.001$ ), which did not differ, $p=.64$. The main effect of Group and Group X Picture Type interaction were not significant, $F \mathrm{~s}<2.21, p \mathrm{~s}>.14$.

\subsubsection{Sadness}

For sadness ratings, both main effects of Group and Picture Type were significant, $F(1,182)=7.23, p<.01$ and $F(3,546)=439.16, p<.001$, respectively. Across all participants, angering pictures $(M=4.95, S D=2.03)$ evoked more sadness than all other picture types, $p<.001$. Fear/disgust pictures $(M=3.64, S D=1.51)$ evoked more sadness than both pleasant $(M=1.31, S D=0.56)$ and neutral $(M=1.72, S D=$ $0.79)$ pictures $(p s<.001)$, and neutral pictures were rated as being more sad than pleasant pictures, $p<.001$. Dysphoric participants perceived the pictures as being more sad than non-dysphoric participants, $p<.01$. The Group X Picture Type interaction was not significant, $F=0.54, p=.65$.

\subsubsection{Anxiety}

For anxiety ratings, the main effects of Group $[F(1,182)=12.93, p<.001]$ and Picture Type $[F(3,546)=275.76, p<.001]$ were significant. Across all participants, the angering $(M=4.37, S D=2.19)$ and fear/disgust $(M=4.55, S D=1.91)$ pictures caused more anxiety than neutral $(M=1.50, S D=0.75)$ and pleasant $(M=2.45, S D=1.33)$ 
pictures $(p s<.001)$, although the former did not differ, $p=.15$. Pleasant pictures caused more anxiety than neutral pictures, $p<.001$. Dysphoric participants perceived the pictures as being more anxiety-provoking than non-dysphoric participants, $p<.001$. The Group X Picture Type interaction was not significant, $F=2.00, p=.11$.

\subsubsection{Blind and constructive patriotism}

Independent t-tests were used to assess group differences on the Patriotism questionnaire. Neither blind nor constructive patriotism differed between dysphoric (blind: $M=33.11, S D=7.17$; constructive: $M=22.37, S D=4.06$ ) and non-dysphoric participants (blind: $M=34.54, S D=6.95$; constructive: $M=22.39, S D=4.19$ ), $t \mathrm{~s}<1.34$, $p s>.18$. As such, it is unlikely that any group differences in patriotism contributed to differences in dysphoric reactions to the (anti-patriotic) angering pictures.

Zero-order correlations $(d f=182)$ examined relationships between blind and constructive patriotism and picture ratings. Individuals high in blind patriotism rated the angering pictures as being more negative $(r=-.31, p<.001)$, more arousing $(r=.15, p<$ $.05)$, more angering $(r=.35, p<.001)$, more fear-provoking $(r=.19, p<.01)$, more disgusting $(r=.38, p<.001)$, more sad $(r=.23, p<.001)$, and more anxiety-provoking $(r=.18, p<.05)$. Individuals high in blind patriotism also rated pleasant and neutral pictures more positively ( $r=18, p<.05$ and $r=.15, p=.05$, respectively). Relationships between blind patriotism and other ratings were $n s(r s<.13, p s>.08)$.

Individuals high in constructive patriotism rated the angering pictures as being more negative $(r=-.15, p<.05)$, more arousing $(r=.20, p<.01)$, more angering $(r=$ $.17, p<.05)$, and more disgusting $(r=.19, p<.05)$. They also rated the pleasant pictures 
as being more joyful $(r=.16, p<.05)$ and the fear/disgust pictures as being more arousing $(r=.18, p<.05)$, more disgusting $(r=.17, p<.05)$, more $\operatorname{sad}(r=.14, p=.05)$, and marginally less joyful $(r=-.14, p=.06)$. Relationships between constructive patriotism and other ratings were $n s(r \mathrm{~s}<.13, p \mathrm{~s}>.08)$.

\subsection{Discussion}

The aim of Study 3 was to clarify why dysphoric participants exhibited potentiated startle eyeblink responses during angering pictures in Study 2, whereas nondysphoric participants did not. Our hypothesis was that such a response was indicative of an aversive or defensive reaction to the images similar to one caused by fear/disgust stimuli, consistent with the notion that depressed or dysphoric individuals have an accentuated sensitivity to avoidance processes and a blunted sensitivity to appetitive processes. Results revealed that, relative to non-dysphoric individuals, dysphoric participants tended to rate the pictures more negative in valence and higher on arousal, anger, fear, disgust, sadness and disgust, independent of picture type. However, in line with predictions, only ratings of fear were moderated by picture type, so that dysphoric participants perceived the angering pictures to be as equally fear-provoking as the fear/disgust pictures.

Together, Studies 1, 2, and 3 provide ample support for the competing influences of motivation, arousal, and valence on the anger-modulated startle eyeblink reflex both in normal populations and in dysphoric individuals. A follow-up to these studies would be to examine the reflex in individuals with heightened approach sensitivity. As such, Study 4 focused on the roles of state and trait approach motivation on the anger- 
modulated startle reflex. It was predicted that high approach motivation would be associated with inhibited eyeblinks during angering pictures, in line with the association between constructive patriotism and anger-evoked eyeblinks in Study 2. However, in this study, personality traits such as reward responsiveness, anger, and dominance were examined as well.

Previous research has shown that increasing the personal relevance of angering stimuli evokes greater approach motivation as measured by relative left frontal cortical activation (Harmon-Jones et al., 2006). As such, to ensure that the angering stimuli engage the behavioral approach system as much as possible, the relevance of the antipatriotic pictures was primed using the Patriotism questionnaire (Schatz et al., 1999), as was done in Studies 2 and 3. In addition, half of participants will be told they will have an opportunity to write an essay about why anti-patriotic acts or attitudes are bad, and that their essay will be used in future research aimed at fostering patriotism (HarmonJones et al., 2006). These individuals are predicted to exhibit increased approached motivation as evidenced in inhibited startle eyeblinks during angering pictures, relative to participants who do not have the expectancy to act against anti-patriotism. 


\section{STUDY 4}

\subsection{Method}

\subsubsection{Participants and design}

One-hundred (60 female) undergraduate students participated in exchange for partial course credit. Data from 27 participants were excluded: two participants chose to stop the experiment before completion; six participants did not complete the experiment due to equipment failure; physiological data from one participant were lost after completion; and physiological data from 18 participants were collected with an inadequate sampling rate. The design was a 2 between-subjects (Essay Expectation: expect, not expect) X 4 within-subjects (Picture Type: angering, pleasant, neutral, fear/disgust) design. There were 36 participants in the essay expectation condition and 37 participants in the no essay expectation condition.

\subsubsection{Materials}

\subsubsection{Personality measures}

The DES-IV (Izard et al., 1993) was used to assess participants' daily emotional experiences. The 36-item questionnaire has 12 scales: interest, enjoyment, surprise, sadness, anger, disgust, contempt, fear, guilt, shame, shyness, and hostility inward. However, due to limitations in time, only items pertaining to interest, enjoyment, sadness, anger, disgust, and fear were administered. Participants were asked to indicate how often they experienced each item in their daily life on a scale of 1 (rarely or never) to 5 (very often). 
The anger subscale of Buss and Perry's (1992) Aggression questionnaire was used to assess participants' anger ( 7 items). Participants were instructed to describe themselves as the honestly saw themselves relative to other individuals the same sex and age. Each item was rated on a scale of 1 (extremely uncharacteristic of me) to 5 (extremely characteristic of me).

Carver and White's (1994) 20-question BIS/BAS scale was administered to assess individual differences in BIS and BAS sensitivity. It is comprised of four scales: BIS, which measures reactions to the expectation of punishment; BAS drive, which measures goal pursuit; BAS reward responsiveness, which assesses positive responses to anticipated reward; and BAS fun seeking, which measures one's desire for and willingness to approach new rewards. Participants were asked to rate each item on a scale of 1 (strongly disagree) to 4 (strongly agree).

The 15-item version of the Hypomanic Personality scale (HYP; Eckblad and Chapman, 1986; Klein et al., 1996) was used to assess proneness to hypomania. High scores on this abbreviated HYP are associated with elevated rates of manic and depressive symptoms (Klein et al., 1996). Sample items include "In unfamiliar surroundings, I am often so assertive and sociable that I surprise myself" (true), and "I have often been so excited about an involving project that I didn't care about eating or sleeping" (true). Participants rated each item as either true or false.

The dominance scale (DOM) from the Personality Assessment Inventory (PAI; Morey, 1991) was used to assess characteristics of dominant personality. The scale 
consists of 12 items (e.g., "I'm a natural leader" and "I say what's on my mind"). Each item was rated on a scale of 1 (false) to 4 (very true).

The BDI-II (Beck et al., 1996; described in Study 2) and CES-D (Radloff, 1977) were administered to assess depressive tendencies. The CES-D is a 20-item instrument used widely to assess depressive symptomatology in the general population. Participants were asked to rate how often they had experienced each feeling (e.g., "I felt depressed") or behavior (e.g., "My sleep was restless") during the past week using a scale of 1 (rarely or none of the time, less than 1 day) to 4 (most or all of the time, 5-7 days).

As in Studies 2 and 3, the Patriotism questionnaire (Schatz et al., 1999) was administered to assess individual differences in blind and constructive patriotism as well as to make the anti-patriotism of the anger pictures more salient, which may prime approach motivational processes in all participants.

\subsubsection{Affective slides}

Sixty-four pictures were presented in randomized order. As in Studies 2 and 3, 16 pictures consisted of anti-patriotic imagery (e.g., flag burning, Osama bin Laden) and were found on the internet; the remaining images were 16 selected from each of the fear/disgust (e.g., snake, bloody hand), neutral (e.g., spoon, rolling pin), and pleasant (e.g., windsailing, partially nude couple) types of the International Affective Picture System (Center for the Study of Emotion and Attention, 1995). Pictures were presented in two blocks; each block contained 32 pictures ( 8 of each picture type), and within each block were three picture sets, each containing 2-3 pictures of each type. Three neutral picture practice trials ( 2 containing startle probes) preceded the 64 pictures. Each picture 
trial consisted of a fixation cross which was presented for 1 second, a picture presented for 6 seconds, and an ITI of 14-18 seconds.

\subsubsection{Startle probe}

The startle probe was a $50 \mathrm{~ms}, 102 \mathrm{~dB}$ burst of white noise presented through stereo headphones. Probes were presented either 4 or 5 seconds after picture onset (32 trials), randomly during the ITI (16 trials), or not at all (16 trials). Each probe type was equally distributed across blocks, sets, and picture types. Furthermore, as in Studies 1 and 2, the 4- and 5- sec probes were varied in order to prevent the individual from learning when the probe would occur and combined for analyses. Only startle eyeblinks to probes presented during affective pictures will be discussed in the present research.

\subsubsection{Procedure}

After informed consent was obtained, participants completed questionnaires pertaining to personality variables. Then, electrodes were affixed below participants' right eyes. Immediately prior to picture viewing, the experimenter determined condition assignment by drawing a slip of paper from an envelope. Participants then viewed pictures in randomized order while the electromyographic (EMG) signals over the left inferior orbicularis oculi (startle eyeblink) were recorded. Participants were told to ignore the intermittent noises they would hear through the headphones, as was done in most past startle research. After the first picture viewing, participants viewed the pictures a second time and rated each on arousal $(1=$ calm, $9=$ excited $)$, valence $(1=$ negative, $9=$ positive), anger, fear, disgust, joy, and sadness (the latter were all rated on a scale of 1 to 9 , where $1=$ not at all and $9=$ very much so). 


\subsubsection{Data collection and reduction}

The procedures used to collect and reduce startle eyeblinks were identical to those used in Study 2. Data from three participants were excluded due to less than half of trials in a given picture type having a good startle response, leaving a total of 70 participants ( $n=35$ per condition) for data analyses involving startle eyeblinks.

\subsection{Results}

\subsubsection{Responses to pictures as a function of essay expectation}

A 2 (Essay Expectation: expect, not expect) X 4 (Picture Type: angering, pleasant, neutral, fear/disgust) ANOVA revealed a main effect of Picture Type on startle eyeblink responses, $F(3,204)=10.31, p<.001$. Across all participants, startle eyeblinks during fear/disgust pictures $(M=0.20, S D=0.37)$ were larger than eyeblinks during all other picture types $(p s<.001)$. Eyeblinks during pleasant pictures $(M=-0.09, S D=$ $0.24)$, neutral pictures $(M=-0.05, S D=0.29)$, and angering pictures $(M=-0.06, S D=$ 0.31) did not differ from one another, $p \mathrm{~s}>.48$. The main effect of Essay Expectation and the Essay Expectation X Picture Type interaction were $n s(p s>24)$. The null interaction can be seen visually in Figure 3.

Between-group means and standard deviations for picture ratings are presented in Table 4. Participants' ratings of the pictures were examined using an Essay Expectation X Picture Type repeated-measures ANOVA for each rating type (valence, arousal, anger, fear, disgust, joy, sadness). 


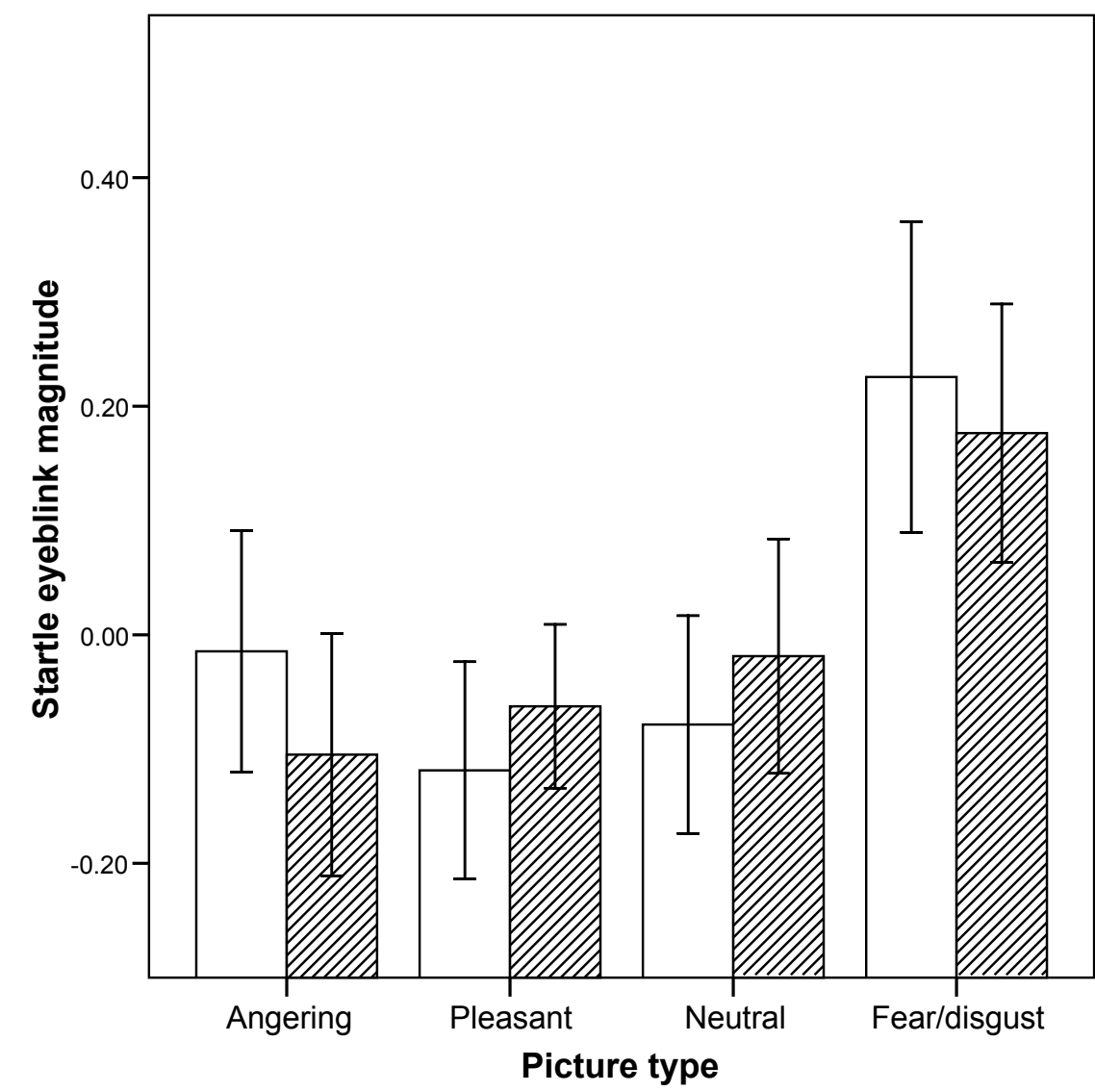

Expectation $\square$ No expectation

Figure 3. Startle eyeblink magnitudes to all picture types as a function of essay expectation in Study 4 (error bars indicate $95 \%$ confidence intervals).

For valence, the main effect of Picture Type was significant, $F(3,210)=187.88$, $p<.001$. Across all participants, pleasant pictures $(M=6.12, S D=1.21)$ were rated more positive than fear/disgust pictures $(M=3.01, S D=1.32)$, angering pictures $(M=$ 2.97, $S D=1.29)$, and neutral pictures $(M=4.95, S D=1.08), p s<.001$. Neutral pictures were rated more positive than fear/disgust pictures and angering pictures, $p s<.001$; the latter two were rated equally negative, $p=.83$. Essay Expectation did not affect valence ratings, $p=.96$. The interaction was also not significant, $p=.48$. 
Table 4

Mean (SD) of picture ratings as a function of essay expectation in Study 4

\begin{tabular}{|c|c|c|}
\hline \multirow[t]{2}{*}{ Rating/Picture Type } & \multicolumn{2}{|c|}{ Mean (SD) } \\
\hline & Essay expectancy & No essay expectancy \\
\hline \multicolumn{3}{|l|}{ Valence } \\
\hline Anger & $2.90(1.51)$ & $3.04(1.04)$ \\
\hline Pleasant & $6.14(1.28)$ & $6.09(1.16)$ \\
\hline Neutral & $5.08(1.20)$ & $4.82(0.95)$ \\
\hline Fear/disgust & $2.90(1.53)$ & $3.11(1.07)$ \\
\hline \multicolumn{3}{|l|}{ Arousal } \\
\hline Anger & $2.70(1.73)$ & $2.54(1.64)$ \\
\hline Pleasant & $4.12(1.59)$ & $4.46(1.73)$ \\
\hline Neutral & $1.82(1.05)$ & $2.12(1.24)$ \\
\hline Fear/disgust & $2.89(1.94)$ & $2.92(2.00)$ \\
\hline \multicolumn{3}{|l|}{ Anger } \\
\hline Anger & $5.03(2.49)$ & 4.95 (1.77) \\
\hline Pleasant & $1.30(0.64)$ & $1.46(0.92)$ \\
\hline Neutral & $1.32(0.67)$ & $1.54(1.06)$ \\
\hline Fear/disgust & $2.57(1.76)$ & $2.97(1.85)$ \\
\hline \multicolumn{3}{|l|}{ Fear } \\
\hline Anger & $3.23(2.18)$ & $3.03(1.82)$ \\
\hline Pleasant & $1.46(0.62)$ & $1.54(0.85)$ \\
\hline Neutral & $1.33(0.70)$ & $1.66(1.09)$ \\
\hline Fear/disgust & $3.66(1.94)$ & $4.02(2.06)$ \\
\hline
\end{tabular}


Table 4 Continued

\begin{tabular}{lcc}
\hline Rating/Picture Type & \multicolumn{2}{c}{ Mean (SD) } \\
\cline { 2 - 3 } & Essay expectancy & No essay expectancy \\
\hline Disgust & $5.28(2.63)$ & $4.81(1.83)$ \\
Anger & $1.58(0.83)$ & $1.50(0.90)$ \\
Pleasant & $1.32(0.61)$ & $1.53(1.04)$ \\
Neutral & $4.88(1.72)$ & $4.89(1.77)$ \\
Fear/disgust & & \\
Joy & $1.53(0.91)$ & $1.60(0.74)$ \\
Anger & $4.26(1.83)$ & $4.92(1.73)$ \\
Pleasant & $2.58(1.56)$ & $2.77(1.35)$ \\
Neutral & $1.50(0.76)$ & $1.54(0.80)$ \\
Fear/disgust & & \\
Sadness & & $2.16(1.82)$ \\
Anger & & $1.43(0.82)$ \\
Pleasant & $1.61(0.87)$ & \\
Neutral & $2.95(1.61)$ & $(2.13)$ \\
Fear/disgust & & \\
\hline
\end{tabular}

For arousal, the main effect of Picture Type was significant, $F(3,210)=80.72, p$ $<.001$. Across all participants, pleasant pictures $(M=4.29, S D=1.66)$ were rated more arousing than fear/disgust pictures $(M=2.91, S D=1.96)$, angering pictures $(M=2.62$, $S D=1.68)$, and neutral pictures $(M=1.97, S D=1.15), p \mathrm{~s}<.001$. Fear/disgust pictures were rated marginally more arousing than angering pictures, $p<.07$, and both 
fear/disgust pictures and angering pictures were rated more arousing than neutral pictures, $p \mathrm{~s}<.001$. The main effect of Essay Expectation and its interaction with Picture Type were not significant, $p \mathrm{~s}>.32$.

Ratings of anger varied significantly by Picture Type, $F(3,210)=150.71, p<$ .001 . Across all participants, angering pictures $(M=4.99, S D=2.14)$ were rated more angering than fear/disgust pictures $(M=2.77, S D=1.81)$, pleasant pictures $(M=1.38$, $S D=0.79)$, and neutral pictures $(M=1.43, S D=0.89), p \mathrm{~s}<.001$. Fear/disgust pictures were rated more angering than pleasant pictures and neutral pictures, $p \mathrm{~s}<.001$, although the latter two did not differ, $p=.83$. The main effect of Essay Expectation and its interaction with Picture Type were not significant, $p \mathrm{~s}>.52$.

Ratings of fear varied significantly by Picture Type, $F(3,210)=81.86, p<.001$. Across all participants, fear/disgust pictures $(M=3.84, S D=2.00)$ were rated more fearful than angering pictures $(M=3.13, S D=1.99)$, pleasant pictures $(M=1.53, S D=$ $0.74)$, and neutral pictures $(M=1.50, S D=0.92), p \mathrm{~s}<.001$. Angering pictures were rated more fearful than pleasant pictures and neutral pictures, $p$ s $<.001$, although the latter two did not differ, $p=.89$. The main effect of Essay Expectation and its interaction with Picture Type were not significant, $p \mathrm{~s}>.39$.

For disgust, the main effect of Picture Type was significant, $F(3,210)=203.03$, $p<.001$. Across all participants, fear/disgust pictures $(M=4.89, S D=1.73)$ and angering pictures $(M=5.04, S D=2.26)$ were equally disgusting, $p=.43$, and both were rated more disgusting than pleasant pictures $(M=1.54, S D=0.86)$ and neutral pictures 
$(M=1.43, S D=0.89), p s<.001$. The latter two did not differ, $p=.57$. The main effect of Essay Expectation and its interaction with Picture Type were not significant, $p \mathrm{~s}>.38$.

For joy, the main effect of Picture Type was significant, $F(3,210)=173.66, p<$ .001 . Across all participants, pleasant pictures $(M=4.59, S D=1.80)$ were rated more joyful than neutral pictures $(M=2.67, S D=1.45)$, fear/disgust pictures $(M=1.52, S D=$ $0.78)$, and angering pictures $(M=1.56, S D=0.82), p \mathrm{~s}<.001$. Neutral pictures were rated more joyful than fear/disgust pictures and angering pictures, $p \mathrm{~s}<.001$, which did not differ, $p=.79$. The main effect of Essay Expectation and its interaction with Picture Type were not significant, $p \mathrm{~s}>.16$.

Ratings of sadness varied significantly by Picture Type, $F(3,210)=95.51, p<$ .001 . Across all participants, angering pictures $(M=4.07, S D=1.97)$ were rated as more sad than fear/disgust pictures $(M=3.06, S D=1.63)$, pleasant pictures $(M=1.38, S D=$ $0.77)$, and neutral pictures $(M=1.81, S D=1.12), p \mathrm{~s}<.001$. Fear/disgust pictures were rated as more sad than pleasant pictures and neutral pictures, $p s<.001$, and neutral pictures were rated as more sad than pleasant pictures, $p<.05$. The main effect of Essay Expectation and its interaction with Picture Type were not significant, $p s>.39$.

\subsubsection{Relationships between picture ratings and startle eyeblinks}

To examine how differences in ratings of the angering pictures might have influenced eyeblink magnitude, participants who were above the median on ratings of anger but below the median on ratings of fear (first group; $n=8$ ) or sadness (second group; $n=8$ ) were identified. A third group consisting of high anger/low disgust only contained four participants and was deemed too small for analysis. 
For the high anger/low fear group, the repeated-measures ANOVA was significant, $F(3,21)=3.01, p=.05$. Post-hoc tests revealed that eyeblinks during fear/disgust pictures $(M=0.38, S D=0.48)$ were greater than eyeblinks during pleasant pictures $(M=-0.18, S D=.30)$ and neutral pictures $(M=-0.14, S D=0.35), p \mathrm{~s}<.05$, and were marginally greater than eyeblinks during angering pictures $(M=0.01, S D=0.28)$, $p=.09$. Eyeblinks during angering, pleasant, and neutral pictures were the same, $p \mathrm{~s}>$ .35 .

The ANOVA for the high anger/low sadness group was also significant, $F(3,21)$ $=2.98, p=.05$. Eyeblinks during fear/disgust pictures $(M=0.32, S D=0.40)$ were greater than eyeblinks during angering pictures $(M=-0.14, S D=0.22)$ and pleasant pictures $(M=-0.11, S D=0.28), p \mathrm{~s}<.05$, and were marginally greater than eyeblinks during neutral pictures $(M=-0.01, S D=0.26), p=.07$. Eyeblinks during angering, pleasant, and neutral pictures were the same, $p \mathrm{~s}>.48$.

Correlations between picture ratings and eyeblinks within each picture type revealed a significant positive relationship between eyeblink magnitude and ratings of arousal for fear/disgust stimuli, $r(67)=.25, p<.05$. A marginally significant relationship was found between eyeblink magnitude and ratings of valence for angering stimuli, so that pictures rated more positively were associated with inhibited blinks, $r(67)=-.21, p$ $=.08$. No other relationships were found, $r \mathrm{~s}<.20, p \mathrm{~s}>.09$.

\subsubsection{Relationships between personality variables and responses to angering pictures}

The means and standard deviations, overall as well as separated by condition, for each personality variable assessed can be found in Table 5. Based on previous research, 
Table 5

Mean (SD) personality ratings across all participants and as a function of essay expectation condition in Study 4

\begin{tabular}{|c|c|c|c|c|}
\hline Personality Variable & All participants & Essay expectation & No essay expectation & $t$ \\
\hline DES Interest & $3.23(0.62)$ & $3.53(0.53)$ & $3.92(0.64)$ & $*-2.85$ \\
\hline DES Enjoyment & $3.93(0.65)$ & $3.88(0.64)$ & $3.96(0.68)$ & -0.52 \\
\hline DES Sadness & $2.31(0.67)$ & $2.12(0.61)$ & $2.49(0.69)$ & $*-2.40$ \\
\hline DES Anger & $2.20(0.66)$ & $2.05(0.63)$ & $2.35(0.67)$ & -1.98 \\
\hline DES Disgust & $1.95(0.62)$ & $1.82(0.58)$ & $2.08(0.64)$ & -1.81 \\
\hline DES Fear & $1.80(0.70)$ & $1.75(0.63)$ & $1.84(0.77)$ & -0.53 \\
\hline BIS Total & $2.97(0.52)$ & $2.94(0.62)$ & $3.00(0.41)$ & -0.45 \\
\hline BAS Total & $3.18(0.40)$ & $3.04(0.35)$ & $3.32(0.39)$ & $*-3.20$ \\
\hline BAS Reward Responsiveness & $3.55(0.35)$ & $3.48(0.34)$ & $3.61(0.35)$ & -1.63 \\
\hline BAS Drive & $2.84(0.62)$ & $2.69(0.64)$ & $2.97(0.57)$ & -1.97 \\
\hline BAS Fun Seeking & $3.11(0.59)$ & $2.90(0.60)$ & $3.32(0.50)$ & $*-3.31$ \\
\hline CES-D & $12.36(7.79)$ & $11.75(8.44)$ & $12.95(7.16)$ & -0.65 \\
\hline BDI-II & $8.10(6.15)$ & $6.89(5.19)$ & $9.24(6.82)$ & -1.64 \\
\hline Anger & $2.17(0.76)$ & $2.04(0.80)$ & $2.30(0.70)$ & -1.44 \\
\hline Hypomania & $22.42(2.66)$ & $21.60(2.10)$ & $23.19(2.92)$ & $*-2.64$ \\
\hline Dominance & $35.34(6.12)$ & $35.08(5.52)$ & $35.60(6.71)$ & -0.36 \\
\hline Blind Patriotism & $31.67(7.29)$ & $32.67(5.39)$ & $30.70(8.72)$ & -1.15 \\
\hline Constructive Patriotism & $23.90(3.47)$ & $23.89(3.39)$ & $23.92(3.60)$ & -0.04 \\
\hline
\end{tabular}

Note. ${ }^{*}$ denotes means which differ significantly $(p<.05)$ between groups. 
it was posited that high approach personality traits (e.g., BAS, aggression, anger, hypomania, patriotism) would be associated with a pattern of responses to angering pictures similar to responses to pleasant pictures (i.e., inhibited eyeblinks), whereas low approach personality traits (e.g., depression, sadness) would show the opposite pattern of responses. Furthermore, although the manipulation of essay expectancy alone did not affect startle eyeblinks in response to affective pictures, it was thought that these personality variables might interact with the expectation (or lack of) to influence startle responses to angering pictures.

To test these hypotheses, regression analyses were conducted in which essay expectation condition (centered), the personality variable of interest (also centered), and their interaction served as predictors for the startle response to angering pictures. In these analyses, the dependent variable was a difference score created by subtracting the eyeblink response during neutral pictures from the response during angering pictures; this was done to reduce variance associated with responses to the pictures in general rather than the affective content. If a significant Essay Expectation X Personality interaction was found, within-condition correlations were conducted to further examine the exact nature of the interaction.

Essay expectation did not interact with personality to significantly predict eyeblink magnitude during angering pictures. A marginal interaction was found between essay expectation and BAS Drive, $\beta=.24, p=.053$. However, within-condition correlations were not significant, making it difficult to interpret this effect. 
Consistent with predictions and replicating Study 2, participants who reported high constructive patriotism evidenced inhibited eyeblinks during angering pictures, $\beta=$ $-.32, p<.05$. Also consistent with Study 2, relationships with depressive traits (i.e., CES-D, BDI-II) trended in the expected direction but were not significant by conventional standards ${ }^{3}$. Zero-order correlations between eyeblink magnitude during all pictures and personality can be found in Table 6 .

\subsubsection{Blind and constructive patriotism and picture ratings}

Zero-order correlations $(d f=70)$ examined relationships between blind and constructive patriotism and picture ratings. Individuals high in blind patriotism rated the angering pictures as being more angering $(r=.25, p<.05)$ and more disgusting $(r=.28$, $p<.05)$, and the pleasant pictures as being more arousing $(r=.26, p<.05)$. All other relationships between blind patriotism and picture ratings were $n s(r s<.19, p s>.10)$. Individuals high in constructive patriotism tended to rate the fear/disgust pictures as being less fear-provoking $(r=-.23, p<.06)$. All other relationships between constructive patriotism and picture ratings were $n s(r \mathrm{~s}<.19, p \mathrm{~s}>.10)$.

3. Due to differences in methodology (i.e., participant recruitment), exact replication of the influence of dysphoria on anger-modulated startle eyeblink was not possible. Nonetheless, relationships between eyeblinks and CES-D/BDI-II were in the predicted direction, albeit below threshold for significance. 
Table 6

Zero-order correlations between personality ratings and eyeblink magnitude (affective-neutral) in Study 4

\begin{tabular}{|c|c|c|c|}
\hline \multirow[t]{2}{*}{ Personality Variable } & \multicolumn{3}{|c|}{ Picture Type } \\
\hline & Angering & Pleasant & Fear/disgust \\
\hline DES Interest & -.11 & -.09 & -.14 \\
\hline DES Enjoyment & -.06 & .04 & -.05 \\
\hline DES Sadness & -.10 & -.01 & -.06 \\
\hline DES Anger & -.02 & .12 & -.13 \\
\hline DES Disgust & -.02 & .00 & .01 \\
\hline DES Fear & -.15 & .03 & .10 \\
\hline BIS Total & -.08 & .02 & .04 \\
\hline BAS Total & -.04 & .09 & .02 \\
\hline BAS Reward Responsiveness & -.05 & .02 & .05 \\
\hline BAS Drive & -.05 & .11 & .09 \\
\hline BAS Fun Seeking & .01 & .04 & -.11 \\
\hline CES-D & .14 & -.10 & .03 \\
\hline BDI-II & .14 & -.08 & .04 \\
\hline Anger & .02 & .01 & -.21 \\
\hline Hypomania & .06 & .11 & -.12 \\
\hline Dominance & -.08 & -.04 & -.16 \\
\hline Blind Patriotism & .20 & .19 & .16 \\
\hline Constructive Patriotism & $* *-.31$ & $*_{-} .28$ & -.21 \\
\hline
\end{tabular}

Note. ${ }^{*} p<.05 ;{ }^{* *} p<.01$ 


\subsection{Discussion}

The aim of Study 4 was twofold. First, it was important to replicate the pattern of startle eyeblinks from Studies 1 and 2. This aim was accomplished, in that no discernable difference between eyeblinks during angering and neutral pictures was found. Furthermore, eyeblinks were greatest during fear/disgust pictures compared to all other picture types. Although eyeblink inhibition during pleasant pictures was not found, meaning that eyeblinks did not differ from those during neutral pictures, this is not entirely uncommon in startle eyeblink research (Grillon and Baas, 2003; Jackson et al., 2000).

The second aim of Study 4 was to examine the influences of state and trait approach motivation on the anger-modulated startle reflex. Just as depressive traits are associated with potentiated eyeblinks during anger (Study 2), likely due perceiving anger as more fear-provoking (Study 3), it was posited that high approach traits (i.e., goalstriving, anger) would be associated with inhibited eyeblinks during anger and low approach traits (i.e., sadness, disgust) would show the opposite pattern. Consistent with predictions, and replicating Study 2, constructive patriotism was associated with inhibited anger-evoked startle eyeblinks. Eyeblink inhibition during pleasant pictures was also associated with constructive patriotism; these relationships were likely due to 
individuals high in constructive patriotism being sensitive to appetitive processes. No other relationships between personality and eyeblink magnitude of any type were found. Manipulating approach motivation did not impact eyeblink magnitude or picture ratings, suggesting that the images were perceived similarly regardless of essay expectation condition. It is possible that participants in both conditions had a desire to act on the anger evoked by the anti-patriotic images, given that all participants were primed by the Patriotism questionnaire. Another possibility is that participants in both conditions believed it to be impossible to act on their anger, thus reducing approach motivation (Harmon-Jones et al., 2006). It is difficult to discern the exact reason for the manipulation failure.

Overall, the results of Study 4 are consistent with the first three studies, as startle eyeblinks during angering pictures did not differ from startle eyeblinks during neutral pictures. 


\section{CONCLUSIONS}

Four studies investigated the anger-modulated startle eyeblink reflex. The aggregate results of these four studies provide evidence for the concurrent roles of valence, arousal, and motivation in the effect of emotion on the startle eyeblink response. Startle eyeblinks to angering stimuli did not differ from eyeblinks to neutral stimuli, despite being rated as more angering, arousing, and negative (Studies 1, 2, and 4). Study 2 also demonstrated that dysphoric individuals evidenced potentiated eyeblinks to angering stimuli much like reactions to fear/disgust stimuli. This is likely due to deficits in appetitive processes and increased sensitivity to negative emotional stimuli observed in depression (e.g., Clark and Watson, 1991; Tomarken and Keener, 1998). In support of this hypothesis, Study 3 demonstrated that dysphoric participants perceived the angering pictures as more fear-provoking than did non-dysphoric participants. Finally, individuals high in constructive patriotism had inhibited eyeblinks during angering pictures (Studies 2 and 4).

Interestingly, other predicted relationships between individual differences in approach and avoidant personality traits and the emotion modulated startle eyeblink were not found. However, this is not entirely inconsistent with the literature. For example, greater blink inhibition during pleasant stimuli has been found in individuals high in trait anger and enjoyment (Amodio and Harmon-Jones, 2011) and BAS sensitivity (Gros, 2011; Hawk and Kowmas, 2003). However, other research did not find relationships between approach traits and eyeblink inhibition (Larson et al., 2000). It is 
possible that detection of these relationships require use of a sample of extreme BAS scores (Gros, 2011).

Additionally, the majority of research investigating individual differences in the emotion modulated startle eyeblink focuses on responses to fear/disgust stimuli. Potentiated eyeblinks to fear/disgust stimuli have been found among individuals high in avoidant traits such as sensitivity to punishment (Caseras et al., 2006), harm avoidance (Corr et al., 1995), and fear (Cook et al., 1991). These effects have also been found in individuals with anxiety disorders such as phobias and PTSD (see Grillon and Baas, 2003, for a review). Conversely, inhibited fear/disgust-evoked eyeblinks occur in individuals with psychopathic traits, suggesting deficits in processing of aversive stimuli (Patrick et al., 1993; but see Justus and Finn, 2007). However, other research has implicated state influences of arousal and aversive anticipation on potentiated startle above and beyond the impact of anxious traits (Nitschke et al., 2002). As such, it is not surprising that individual differences did not relate to fear/disgust-evoked eyeblink potentiation in the present studies, given that defensive states were not manipulated.

Lang (1995) described the startle eyeblink as a reflex specific to defensive motivation elicited by stimuli negative in affective valence. That is, only when presented with aversive stimuli is the defensive system primed and thus the probed startle response potentiated. As such, eyeblink potentiation is often considered fear- or threat-specific, because that which elicits direct threat of physical harm is most activating of defensive 
motivation (Bradley et al., 1999). For example, one study found that fear scenes elicited larger eyeblinks compared to disgust scenes, despite being rated equally arousing (Balaban and Taussig, 1994). However, Yartz and Hawk (2002) failed to replicate this research, instead finding that potentiation occurred in response to negative emotion regardless of the specific aversive content. Furthermore, arousing, unpleasant stimuli depicting human attack, animal attack, and contamination elicited equally potentiated eyeblink responses, despite only the first two picture types being classified as most threating to survival (Bradley et al., 2001).

Yet, the results of the present research support a more complex model encompassing the aggregate influences of three different factors - motivation, arousal, and valence - on emotional processing as revealed in the startle eyeblink responses. In light of anger's identity as a negative affect with approach (or appetitive) motivational properties similar to positive affects, anger was uniquely qualified to test this multidimensional approach to the startle reflex. According to the arousal/valence hypothesis, the anger-evoked startle eyeblink should be potentiated similar to eyeblinks to fear/disgust, because anger is similar to fear/disgust in being high in arousal and negative in valence. The results did not support this hypothesis. The prediction that angering stimuli would evoke inhibited eyeblink responses, much like pleasant stimuli, due to activation of appetitive motivation was also not supported. Rather, the competing influences of all three factors produced an anger-related eyeblink undifferentiated from that evoked by neutral stimuli, suggesting that a multi-dimensional model of the 
emotion-modulated startle eyeblink is most accurate. In other words, visual stimuli likely need to evoke an approach-motivated positive affective state to cause an inhibited startle eyeblink response, and they need to evoke a withdrawal-motivated negative affective state to cause a potentiated startle eyeblink response. As revealed in the present three experiments, an approach-motivated negative affective state of anger causes a startle eyeblink response that is similar in magnitude to that caused by neutral stimuli.

In paradigms investigating emotional processes, motivational properties of emotion are often shadowed by valence and arousal. Research utilizing the startle eyeblink, one of the most widely used physiological indexes of emotion for the last 20 years, is not an exception, as most investigators tend to use paradigms that confound valence and arousal with motivational direction. However, the present research supports the notion that investigators should take into consideration the simultaneous influences of motivation, arousal, and valence on physiological responses to affective stimuli. 


\section{REFERENCES}

Amodio, D. M., Harmon-Jones, E., 2011. Trait emotions and startle eyeblink responses to affective pictures: on the unique relationship of trait anger. Emotion 11, 47-51.

Balaban, M. T., Taussig, H. N., 1994. Salience of fear/threat in the affective modulation of the human startle blink. Biological Psychology 38, 117-131.

Beck, A. T., Steer, R. A., Brown, G. K., 1996. The BDI-II Manual. The Psychological Corp, San Antonio, TX.

Berkman, E. T., Lieberman, M. D., 2010. Approaching the bad and avoiding the good: Lateral prefrontal cortical asymmetry distinguishes between action and valence. Journal of Cognitive Neuroscience 22, 1970-1979.

Berkowitz, L., 1993. Pain and aggression: some findings and implications. Motivation and Emotion 17, 277-293.

Blumenthal, T. D., Cuthbert, B. N., Filion, D. L., Hackley, S., Lipp, O. V., van Boxtel, A., 2005. Committee report: guidelines for human startle eyeblink electromyographic studies. Psychophysiology 42, 1-15.

Bradley, M. M., Codispoti, M., Cuthbert, B. N., Lang, P. J., 2001. Emotion and motivation I: defensive and appetitive reactions in picture processing. Emotion 1, 276-298.

Bradley, M. M., Cuthbert, B. N., Lang, P. J., 1990. Startle reflex modification: emotion or attention? Psychophysiology 27, 513-522. 
Bradley, M. M., Cuthbert, B. N., Lang, P. J., 1999. Affect and the startle reflex. In: Dawson, M. E., Schell, A. M., Bohmelt, A. H., Eds.), Startle Modification: Implications for Neuroscience, Cognitive Science, and Clinical Science. Cambridge University Press, New York, pp. 157-183.

Buss, A. H., Perry, B., 1992. The aggression questionnaire. Journal of Personality and Social Psychology 63, 452-459.

Carver, C. S., Harmon-Jones, E., 2009. Anger is an approach-related affect: evidence and implications. Psychological Bulletin 135, 183-204.

Carver, C. S. White, T. L., 1994. Behavioral inhibition, behavioral activation, and affective responses to impending reward and punishment: the BIS/BAS scales. Journal of Personality and Social Psychology 67, 319-333.

Caseras, F. X., Fullana, M. A., Riba, J., Barbanoj, M. J., Aluja, A., Torrubia, R., 2006. Influence of individual differences in the behavioral inhibition system and stimulus content (fear versus blood-disgust) on affective startle reflex modulation. Biological Psychology 72, 251-256.

Clark, L. A., Watson, D., 1991. Tripartite model of anxiety and depression: psychometric evidence and taxonomic implications. Journal of Abnormal Psychology 100, 316-336.

Coan, J. A., Allen, J. J. B., 2004. Frontal EEG asymmetry as a moderator and mediator of emotion. Biological Psychology 67, 7-49. 
Cook III, E. W., Hawk, L. W., Davis, T. L., Stevenson, V. E., 1991. Affective individual differences in startle reflex modulation. Journal of Abnormal Psychology 100, 513.

Corr, P. J., Wilson, G. D., Fotiadou, M., Kumari, V., Gray, N. S., Checkley, S., Gray, J. A., 1995. Personality and affective modulation of the startle reflex. Personality and Individual Differences 19, 543-553.

Cuthbert, B. N., Bradley, M. M., Lang, P. J., 1996. Probing picture perception: activation and emotion. Psychophysiology 33, 103-111.

Davidson, R. J., 1998. Anterior electrophysiological asymmetries, emotion, and depression: conceptual and methodological conundrums. Psychophysiology 35, 607-614.

Davidson, R. J., Ekman, P., Saron, C. D., Senulis, J. A., Friesen, W. V., 1990. Approachwithdrawal and cerebral asymmetry: emotional expression and brain physiology I. Journal of Personality and Social Psychology 58, 330-341.

Davis, M., 1997. Neurobiology of fear responses: the role of the amygdala. Journal of Neuropsychiatry and Clinical Neurosciences 9, 382-402.

Eckblad, M., Chapman, L. J., 1986. Development and validation of a scale for hypomanic personality. Journal of Abnormal Psychology 95, 214-222. 
Ford, B. Q., Tamir, M., Brunye, T. T., Shirer, W. R., Mahoney, C. R., Taylor, H. A., 2010. Keeping your eyes on the prize: anger and visual attention to threats and rewards. Psychological Science 21, 1098-1105.

Gautier, C. H., Cook III, E. W., 1997. Relationships between startle and cardiovascular reactivity. Psychophysiology 34, 97-96.

Grillon, C., Baas, J., 2003. A review of the modulation of the startle reflex by affective states and its application in psychiatry. Clinical Neurophysiology 114, 15571579.

Gros, D. E., 2011. Startle inhibition to positive-activated compared to neutral stimuli: variations in self-reported behavioral approach. Journal of Psychopathology and Behavioral Assessment 33, 308-314.

Harmon-Jones, E., 2003. Anger and the behavioral approach system. Personality and Individual Differences 35, 995-1005.

Harmon-Jones, E., 2004. On the relationship of anterior brain activity and anger: examining the role of attitude toward anger. Cognition and Emotion 18, 337-361.

Harmon-Jones, E., 2007. Trait anger predicts relative left frontal cortical activation to anger-inducing stimuli. International Journal of Psychophysiology 66, 154-160.

Harmon-Jones, E., Allen, J. J. B., 1997. Behavioral activation sensitivity and resting frontal EEG asymmetry: covariation of putative indicators related to risk for mood disorders. Journal of Abnormal Psychology 106, 159-163. 
Harmon-Jones, E., Allen, J. J. B., 1998. Anger and frontal brain activity: EEG asymmetry consistent with approach motivation despite negative affective valence. Journal of Personality and Social Psychology 74, 1310-1316.

Harmon-Jones, E., Harmon-Jones, C., Abramson, L. Y., Peterson, C. K., 2009. PANAS positive activation is associated with anger. Emotion 9, 183-196.

Harmon-Jones, E., Lueck, L., Fearn, M., Harmon-Jones, C., 2006. The effect of personal relevance and approach-related action expectation on relative left frontal cortical activity. Psychological Science 17, 434-440.

Harmon-Jones, E., Peterson, C. K., 2009. Supine body position reduces neural response to anger evocation. Psychological Science 20, 1209-1210.

Harmon-Jones, E., Peterson, C. K., Harris, C. R., 2009. Jealousy: novel methods and neural correlates. Emotion 9, 113-117.

Harmon-Jones, E., Sigelman, J. D., Bohlig, A., Harmon-Jones, C., 2003. Anger, coping, and frontal cortical activity: the effect of coping potential on anger-induced left frontal activity. Cognition and Emotion 17, 1-24.

Hawk, L. W., Kowmas, A. D., 2003. Affective modulation and prepulse inhibition of startle among undergraduates high and low in behavioral inhibition and approach. Psychophysiology 40, 131-138.

Hawk, L. W., Stevenson, V. E., Cook III, E. W., 1992. The effects of eyelid closure on affective imagery and eyeblink startle. Journal of Psychophysiology 6, 299-310. 
Heller, W., 1990. The neuropsychology of emotion: developmental patterns and implications for psychopathology. In: N. L. Stein, B. Leventhal, T. Trabasso (Eds.), Psychological and biological approaches to emotion. Erlbaum, Hillsdale, NJ, pp. 167-211.

Hitchcock, J. M., Davis, M., 1991. The efferent pathway of the amygdala involved in conditioned fear as measured with the fear-potentiated startle paradigm. Behavioral Neuroscience 105, 826-842.

Izard, C. E., 1991. The psychology of emotions. New York: Plenum Press.

Izard, C. E., Libero, D. Z., Putnam, P., Haynes, O. M., 1993. Stability of emotional experiences and their relations to trait personality. Journal of Personality and Social Psychology 64, 847-860.

Jackson, D. C., Malmstadt, J. R., Larson, C. L., Davidson, R. J., 2000. Suppression and enhancement of emotional responses to unpleasant pictures. Psychophysiology $37,515-522$.

Justus, A. N., Finn, P. R., 2007. Startle modulation in non-incarcerated men and women with psychopathic traits. Personality and Individual Differences 43, 2057-2071.

Klein, D. N., Lewinsohn, P. M., Seeley, J. R., 1996. Hypomanic personality traits in a community sample of adolescents. Journal of Affective Disorders 38, 135-143.

Lang, P. J., 1995. The emotion probe: studies of motivation and attention. American Psychologist 50, 372-385. 
Lang, P. J., Bradley, M. M., Cuthbert, B. N., 1990. Emotion, attention, and the startle reflex. Psychological Review 97, 377-398.

Lang, P.J., Bradley, M.M., \& Cuthbert, B.N. (2008). International affective picture system (IAPS): affective ratings of pictures and instruction manual. Technical Report A-8. University of Florida, Gainesville, FL.

Larson, C. L., Ruffalo, D., Nietert, J. Y., Davidson, R. J., 2000. Temporal stability of the emotion-modulated startle response. Psychophysiology 37, 92-101.

Mikels, J. A., Fredrickson, B. L., Larkin, G. R., Lindberg, C. M., Maglio, S. J., ReuterLorenz, P. A., 2005. Emotional category data on images from the International Affective Picture System. Behavior Research Methods 37, 626-630.

Mikulincer, M., 1988. Reactance and helplessness following exposure to unsolvable problems: the effects of attributional style. Journal of Personality and Social Psychology 54, 679-686.

Miller, M. W., Patrick, C. J., Levenston, G. K., 2002. Affective imagery and the startle response: probing mechanisms of modulation during pleasant scenes, personal experiences, and discrete negative emotions. Psychophysiology 39, 519-529.

Morey, L. C., 1991. The personality assessment inventory: professional manual. Psychological Assessment Resources, Fort Worth, TX.

Neumann, D. R., Hammond, F., Norton, J., Blumenthal, T., 2011. Using startle to objectively measure anger and other emotional responses after traumatic brain injury: a pilot. Journal of Head Trauma Rehabilitation 26, 375-383. 
Nitschke, J. B., Larson, C. L., Smoller, M. J., Navin, S. D., Pederson, A. J. C., Ruffalo D., ... Davidson, R. J., 2002. Startle potentiation in aversive anticipation: evidence for state but not trait effects. Psychophysiology 39, 254-258.

Patrick, C. J., Bradley, M. M,, Lang, P. J., 1993. Emotion in the criminal psychopath: startle reflex modulation. Journal of Abnormal Psychology 102, 82-92.

Peterson, C. K., Gravens, L. C., Harmon-Jones, E., 2011. Asymmetric frontal cortical activity and negative affective responses to ostracism. Social, Cognitive, and Affective Neuroscience 6, 277-285.

Peterson, C. K., Shackman, A. J., Harmon-Jones, E., 2008. The role of asymmetrical frontal cortical activity in aggression. Psychophysiology 45, 86-92.

Radloff, L. S., 1977. The CES-D scale: a self-report depression scale for research in the general population. Applied Psychological Measurement 1, 385-401.

Schatz, R. T., Staub, E., Lavine, H., 1999. On the varieties of national attachment: blind versus constructive patriotism. Political Psychology 20, 151-174.

Sutton, S. K., Davidson, R. J., 1997. Prefrontal brain asymmetry: a biological substrate of the behavioral approach and inhibition systems. Psychological Science 8, 204210.

Tomarken, A. J., Keener, A. D., 1998. Frontal brain asymmetry and depression: a selfregulatory perspective. Cognition Emotion 12, 387-420. 
Wilkowski, B. M., Meier, B. P., 2010. Bring it on: angry facial expressions potentiate approach-motivated motor behavior. Journal of Personality and Social Psychology 98, 201-210.

Witvliet, C. V. O., Vrana, S. R., 1995. Psychophysiological responses as indices of affective dimensions. Psychophysiology 32, 436-443.

van Boxtel, A., Boelhouwer, A. J. W., Bos, A. R., 1998. Optimal EMG signal bandwidth and interelectrode distance for the recording of acoustic, electrocutaneous and photic blink reflexes. Psychophysiology 35, 690-697.

Vrana, S. R., 1994. Startle reflex response during sensory modality specific disgust, anger, and neutral imagery. Journal of Psychophysiology 8, 221-218.

Vrana, S. R., Spence, E. L., Lang, P. J., 1988. The startle probe response: a new measure of emotion? Journal of Abnormal Psychology 97, 487-491.

Yartz, A. R., Hawk, L. W., 2002. Addressing the specificity of affective startle modulation: fear versus disgust. Biological Psychology 59, 55-68. 


\section{VITA}

Name: $\quad$ Carly Kathryn Peterson

Address: $\quad$ VA Puget Sound Health Care System, American Lake Division, 9600 Veterans Drive (A-116-B), Tacoma, WA 98493

Email Address: carlypeterson@gmail.com

Education: $\quad$ B.A., Psychology, University of Wisconsin, 2005

M.S., Psychology, Texas A\&M University, 2009

Ph.D., Psychology, Texas A\&M University, 2012 